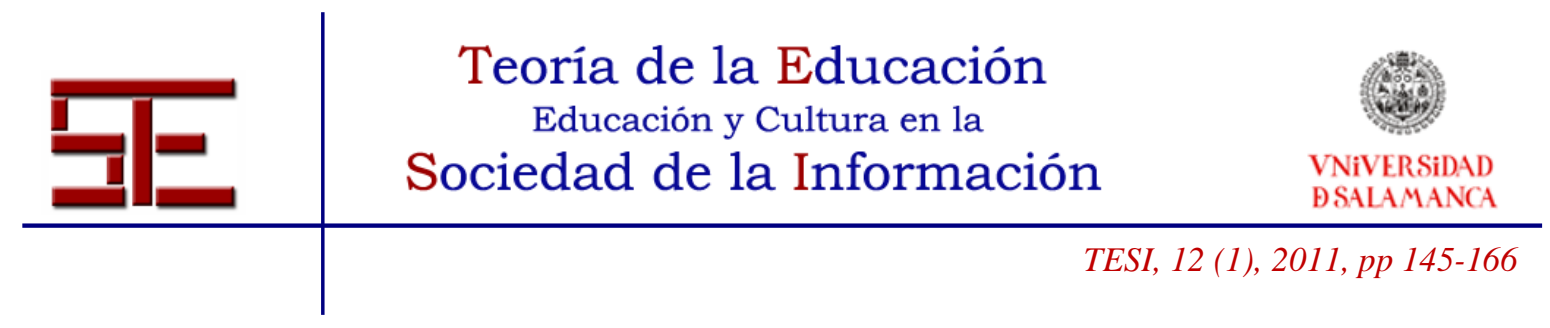

\title{
USANDO LA WEB 2.0 PARA INFORMARSE E INFORMAR. UNA EXPERIENCIA EN EDUCACIÓN SUPERIOR
}

Resumen: En un contexto donde la información se ha convertido en la principal material prima y las pantallas inundan el espacio público y privado, las instituciones educativas han de proporcionar herramientas para la comprensión del mundo en el que se vive, la promoción del pensamiento crítico o la construcción de una ciudadanía activa y responsable. En este sentido, la lectura crítica de los mass media y la producción de mensajes mediáticos por parte del estudiantado se torna fundamental.

Para ello, el rol del docente ha de cambiar para convertirse en un facilitador de espacios de aprendizaje que permitan al estudiantado adquirir las competencias necesarias para enfrentarse a los retos del siglo XXI y la Web 2.0 se convierte en una herramienta pedagógica interesante para aprender haciendo, buscando, interactuando y colaborando (Cobo y Pardo, 2007).

El presente artículo tiene como finalidad difundir una experiencia de innovación educativa que se ha desarrollado en la Universitat Jaume I de Castellón (España) donde el estudiantado de Educación Cívica y Social ha utilizado la Web 2.0 para buscar información, seleccionarla y analizarla para luego producir sus propios discursos informativos tanto textuales como audiovisuales al mismo tiempo que se alfabetizaban digitalmente. El proyecto fue evaluado por el estudiantado a través de un cuestionario tipo Likert y sus resultados mostraron una alta valoración tanto de la introducción de las TIC en la asignatura como del aprendizaje producido por el planteamiento de trabajo.

Palabras clave: Alfabetización digital; Educación en Medios; TIC; Educación Superior.

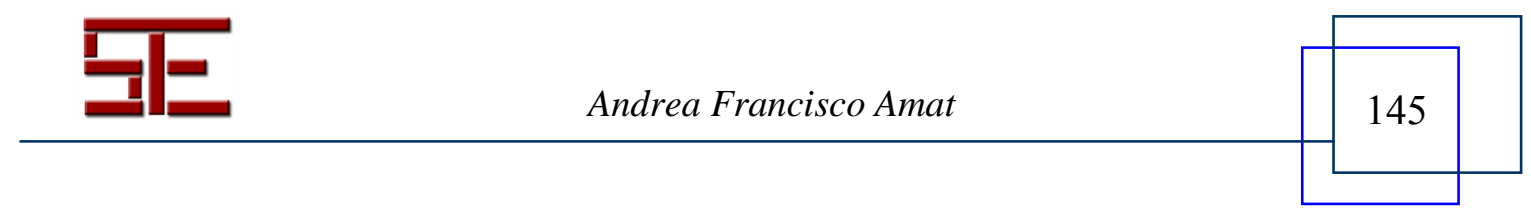




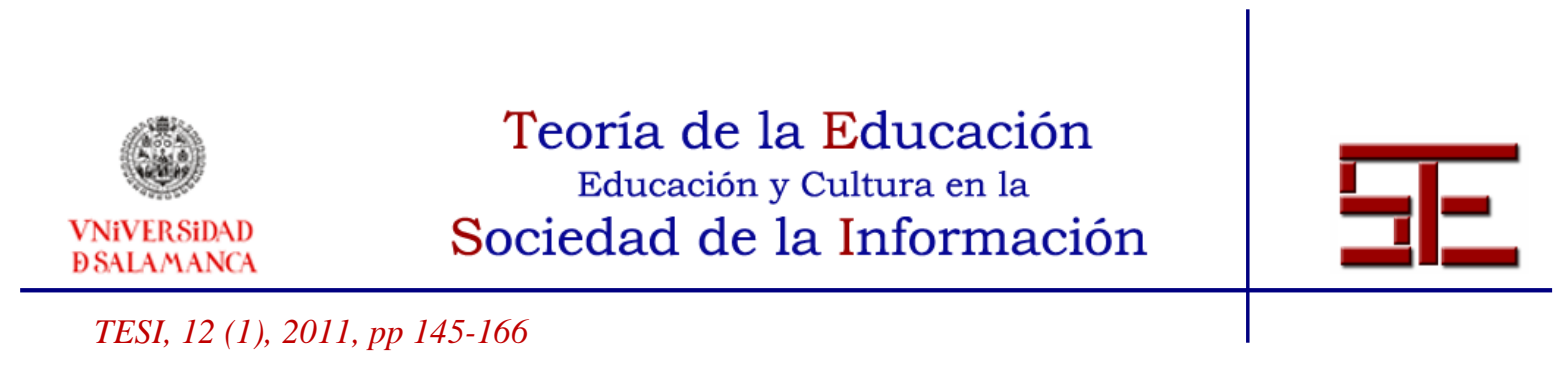

\title{
USING WEB 2.0 TO OBTAIN AND CONSTRUCT INFORMATION. AN EXPERIENCE IN HIGHER EDUCATION
}

\begin{abstract}
In a context where the information has turned into a principal source and where media screens flood the public and private spaces, educational institutions have to provide the tools for the comprehension of the lived world, the promotion of the critical thinking or the construction of active and responsible citizenship. In this respect, the critical reading of the mass media and the production of media messages on the part of the student body becomes fundamental.
\end{abstract}

Therefore, the role of the teacher has to change into a facilitator of spaces of learning that allow the student body to acquire the necessary capacities to face the challenges of the 21 st century and Web 2.0 turns into an interesting pedagogic tool to learn through practice, information searching, interacting and collaborating (Cobo and Pardo, 2007).

The purpose of the present article is to share the experiences of educational innovation developed in Castellón's Universitat Jaume I (Spain) where students of Civic and Social Education have used Web 2.0 to seek, select and analyze information and then to produce their own informative material, both textual and audio-visual, in the process of learning alphabetized digital knowedge and practice. The project was highy evaluated by the student body through a Likert type questionnaire survey.

Keywords: Digital Literacy; Media Literacy; ICT; Higher Education.

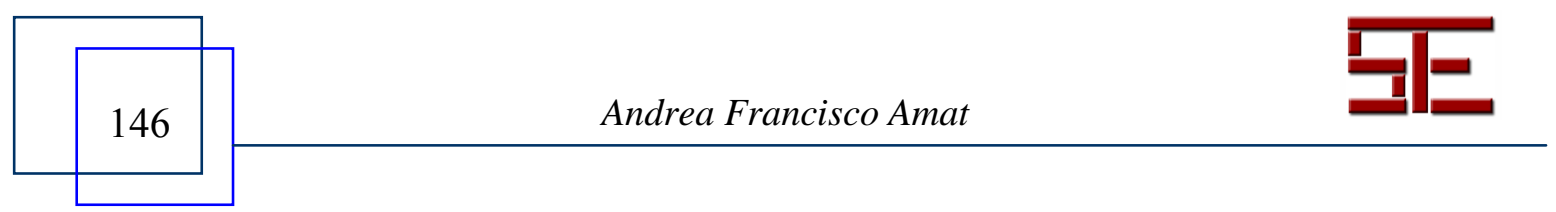




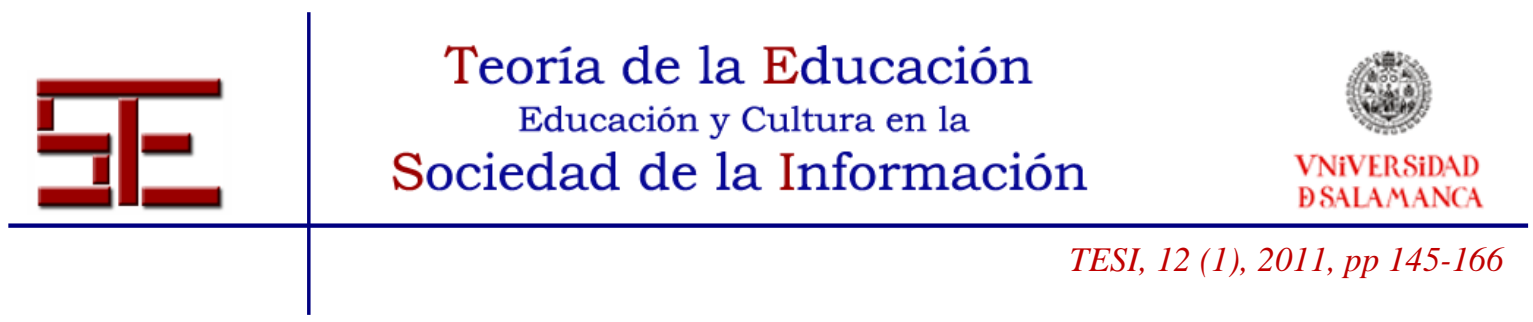

\title{
USANDO LA WEB 2.0 PARA INFORMARSE E INFORMAR. UNA EXPERIENCIA EN EDUCACIÓN SUPERIOR
}

Fecha de recepción: 08/12/2010; fecha de aceptación: 11/02/2011; fecha de publicación: 31/03/2011

\author{
Andrea Francisco Amat \\ afrancis@edu.u1i.es \\ Universitat Jaume I
}

\section{INTRODUCCIÓN}

El presente artículo se divide en 4 apartados. En el primero se realiza una breve panorámica al contexto actual, la sociedad de la información, y sus consecuencias en el campo de la educación. Posteriormente, en la segunda parte, se profundiza en las competencias necesarias para pasar de la sociedad de la información a la sociedad del conocimiento, haciendo hincapié en la necesidad de una nueva alfabetización, de una introducción de las TIC en el aula que supere la visión instrumental, del cambio del rol del docente en el siglo XXI y del uso de la Web 2.0 como herramienta pedagógica para aprender haciendo, buscando, interactuando y colaborando. A continuación, se relata la experiencia de innovación educativa desarrollada en la Univesitat Jaume I de Castellón donde se utilizó la Web 2.0 para informarse e informar. En este apartado se explican varios proyectos realizados por el estudiantado y sus actitudes hacia la introducción de las TIC en la asignatura y la valoración que realizan sobre su propio aprendizaje a partir de un cuestionario tipo Likert que se aplicó una vez finalizada la experiencia. En la última parte del artículo se resumen las principales conclusiones.

\section{EL CONTEXTO ACTUAL: LA SOCIEDAD DE LA INFORMACIÓN}

Estamos viviendo en la llamada sociedad de la información. Como explica Manuel Castells (2001), en este nuevo paradigma la generación, el procesamiento y la transmisión de información se convierten en las fuentes fundamentales de la productividad y del poder. Entre los rasgos principales de esta sociedad nos encontramos con que la información es la materia prima y los efectos de las nuevas tecnologías de la información tienen gran capacidad de penetración en la vida social.

Los canales de comunicación se multiplican, la tecnología no para de innovar y el tiempo dedicado a su consumo de los media crece a un ritmo vertiginoso, con el

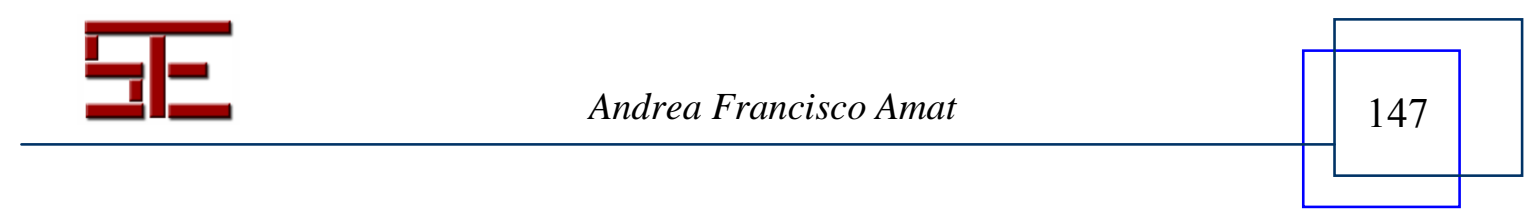




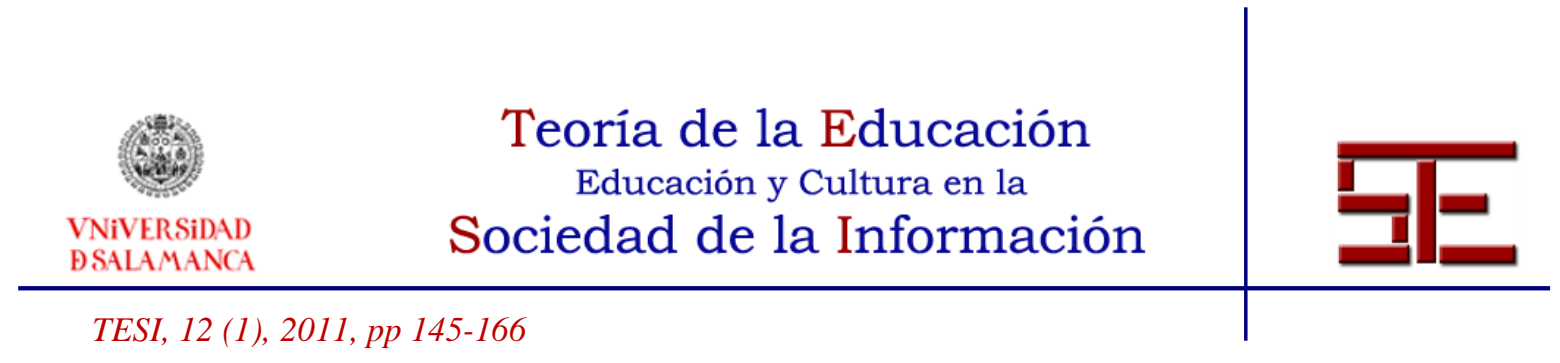

aumento de pantallas que invaden los espacios de la sociedad y de nuestra vida cotidiana. Las imágenes y la información fluyen por doquier inundando el espacio público y privado.

La multiplicación de medios y de contenidos nos ha llevado desde hace un tiempo a una saturación de información (Acaso, 2006; Aparici y García Mantilla, 2008; Bauman, 2007; Díaz Nosty, 1996; Francisco, 2008 y 2009). El mundo ha producido en 30 años más informaciones que en el transcurso de los 5000 años precedentes y un solo ejemplar de la edición dominical del New York Times contiene más información que la que durante toda su vida podía adquirir una persona del siglo VII (Ramonet, 2000). Internet ha multiplicado exponencialmente el volumen de información al alcance de un clic. A lo largo de 2006 el volumen mundial de información digital creada, capturada y replicada fue de 161.000 millones de gigabytes. Esto supone unos tres millones de veces más que la información contenida en todos los libros escritos a lo largo de la historia y el volumen continúa creciendo (Nafria, 2008). La información, durante mucho tiempo difícil y costosa, se ha tornado en prolífica y pululante. Junto con el agua y el aire, se trata indudablemente del elemento que más abunda en el planeta. "Cada vez menos cara, en la medida en que aumenta su caudal, pero como sucede con el aire y el agua, cada vez más contaminada" (Ramonet, 2000: 218).

Hace más de un siglo que nos encaminamos hacia la sensación contemporánea de supersaturación, al desbordamiento de un entorno que rezuma señales y carteles y genera reacciones desabridas ante la sobrecarga informativa. Como describe Gitlin (2005), en la MSNBC ponen una entrevista, un experto habla sobre Irak y las armas de destrucción masiva. En el ángulo inferior derecho está el logotipo de la cadena; a la izquierda, el promedio industrial del Dow Jones, junto a la temperatura actual y el mapa del tiempo. Después suenan las tres campanadas de la NBC y la imagen de la entrevista se reduce de tamaño; simultáneamente, aparecen los titulares en la parte inferior de la pantalla. Y luego viene un corte de dos anuncios de treinta segundos mientras las imágenes parpadean a un promedio de más de una imagen por segundo. Un torrente de información que se multiplica cuando navegamos por Internet.

Estamos hablando de un cambio de tal magnitud que podemos calificarlo de revolución y es necesario pararse a pensar en cómo está afectando a los seres humanos, tanto en el plano cognitivo como emocional. Tenemos que replantearnos el proceso de enseñanza aprendizaje en este nuevo contexto. Sobre todo si tenemos en cuenta que a este fenómeno de multiplicación de canales y de información, hay que sumarle el aumento

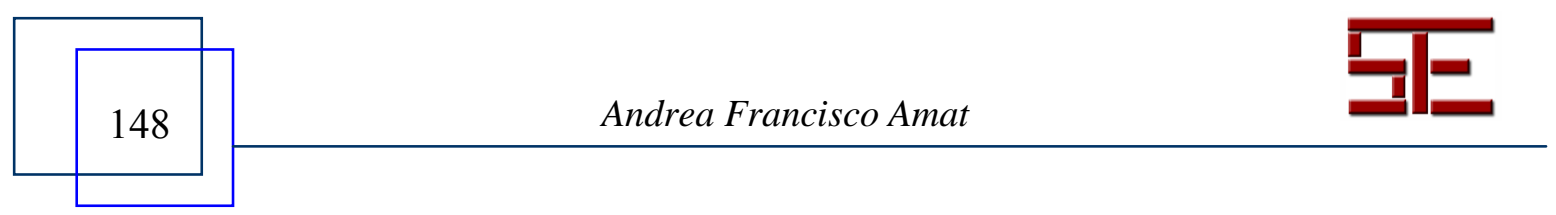




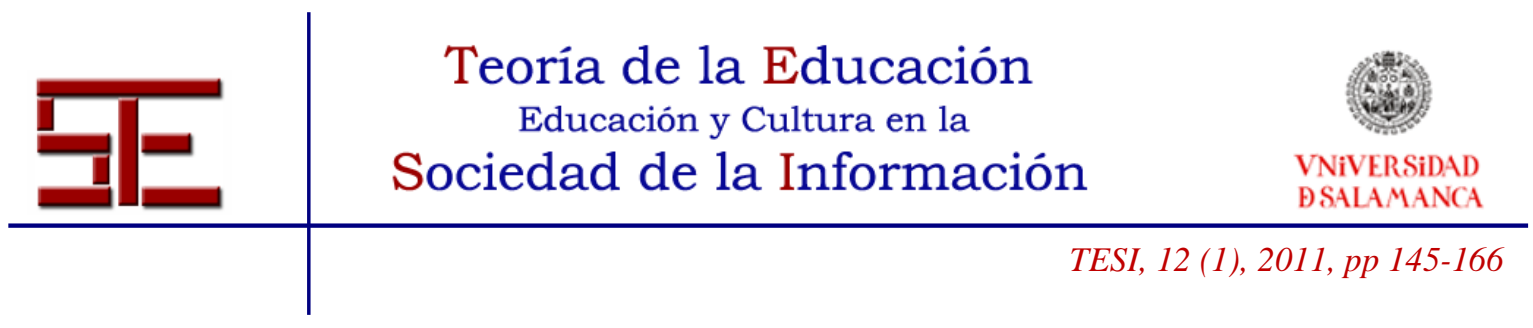

del tiempo dedicado al consumo de mensajes mediáticos de los jóvenes, según se desprende de varias investigaciones (Aranda, Sánchez-Navarro, Tabernero, 2009; Barómetro comunicación, 2010; Injuve, 2008; Marta Lazo, 2007).

A modo de ejemplo, los jóvenes del País Valenciano, Cataluña y las Islas Baleares, dedican al consumo de medios de comunicación un total de 6 horas y 49 minutos cada día, de este tiempo casi 2 horas son las dedicadas a Internet. El 72\% de los jóvenes españoles acceden a la Red todas las semanas y se consideran internautas habituales. Los tres principales usos de Internet por parte de los jóvenes son: el correo electrónico $(86 \%)$, el chat o la mensajería instantánea $(76 \%)$ y las redes sociales $(70 \%)$. Cabe destacar la rápida penetración de estas últimas, con cifras como las de Facebook que desde su lanzamiento en 2004 ha conseguido más de 500 millones de usuarios, de los cuales el $50 \%$ entra cada día a su perfil. Los adolescentes las utilizan como mucha frecuencia y hacen de las redes sociales un instrumento para relacionarse con los amigos y para expresar públicamente sus opiniones o intereses y no las utilizan como herramienta para sus estudios, ni para estar en contacto con sus familiares o profesores.

Pero, a pesar de la presencia de Internet en la vida de los jóvenes, las instituciones educativas no le ha dedicado suficiente atención al fenómeno y encontramos que el aprendizaje del uso de la Red es fundamentalmente informal y apenas el $20 \%$ afirma haber aprendido en clase, academias o asociaciones de tiempo libre y esto tiene sus consecuencias. Porque el aumento de la información no se traduce en una mejor compresión del mundo. Se observa que hay un exceso e inmediatez de la misma (Gitlin, 2005). Esta saturación es necesario aprender a gestionarla para poder recuperar un espacio de autonomía y de pensamiento crítico. Lo importante no es adquirir información, sino integrar la información en el saber, el saber en conocimiento y el conocimiento en cultura

El alfabetismo mediático de los jóvenes no ha mejorado con el incremento del acceso a las TIC, aunque están más conectados durante más tiempo. Su aparente facilidad para manejar ordenadores esconde algunos problemas preocupantes. Diversas investigaciones (British Library y JISC, 2008; Hernández, 2009) muestran que los jóvenes tienen una compresión pobre de sus necesidades de información y encuentran dificultades para desarrollar estrategias de búsqueda efectivas. Además, enfrentados a una larga lista de resultados de búsqueda se les hace difícil evaluar la relevancia de los materiales. En definitiva, les faltan habilidades críticas y analíticas para juzgar la relevancia y la confiabilidad de lo que encuentran en la red. En este sentido, es

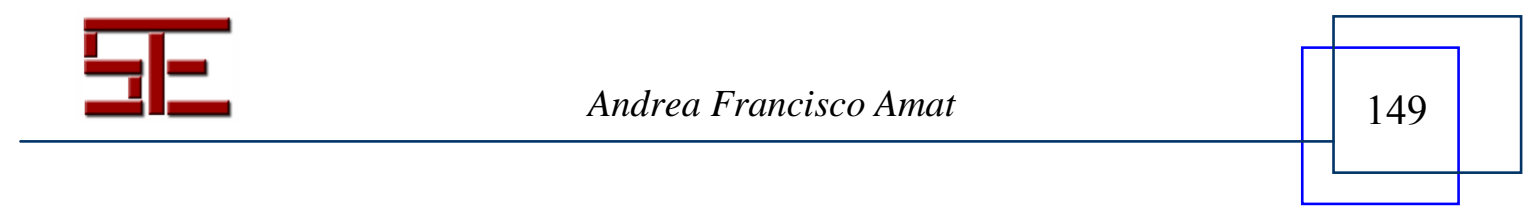




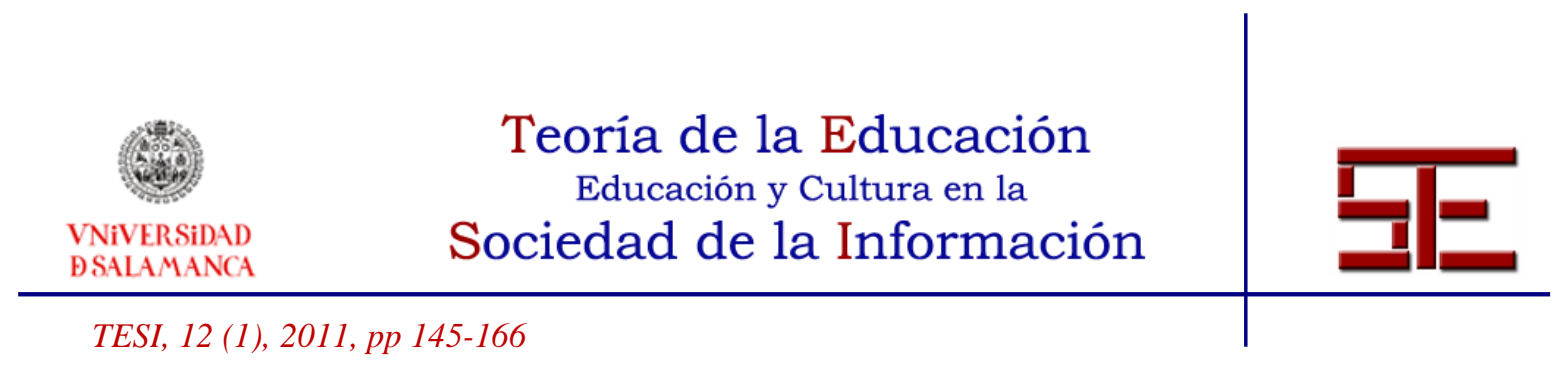

importante aprender estrategias de búsqueda de información. De hecho, según estudios (Fuentes, 2001), es más importante el hecho de ser estratégico en la búsqueda de información que poseer amplios conocimientos acerca de las herramientas de búsqueda y los medios informáticos.

Si queremos pasar de la sociedad de la información a la sociedad del conocimiento, los centros de educación formal y no formal necesitan incluir aprendizajes que preparen a los jóvenes para el siglo XXI. Actualmente, los ciudadanos necesitamos mayor cantidad $\mathrm{y}$ calidad de educación donde la alfabetización mediática ha de tener un espacio relevante. Una formación en competencias informacionales y digitales que tiene que darse en todos los niveles y que la educación superior ha de contemplar (Area, 2010a).

\section{CAMINAR HACIA UNA SOCIEDAD DEL CONOCIMIENTOS}

\subsection{Una nueva alfabetización. La propuesta de la Educación en Medios}

Para vivir, aprender y trabajar con éxito en una sociedad cada vez más compleja, rica en información y basada en el conocimiento, estudiantes y docentes deben utilizar la tecnología digital con eficacia. En un contexto educativo sólido, las Tecnologías de la Información y la Comunicación (TIC) pueden ayudar a los estudiantes a adquirir las capacidades necesarias para llegar a ser: competentes para utilizar tecnologías de la información; buscadores, analizadores y evaluadores de información; solucionadores de problemas y tomadores de decisiones; usuarios creativos y eficaces de herramientas de productividad; comunicadores, colaboradores, publicadores y productores; y ciudadanos informados, responsables y capaces de contribuir a la sociedad. (Area, 2008; Hernández, 2009; UNESCO, 2008)

En esta línea se enmarca la propuesta de la Educación en Medios o Media Literacy. Esta tiene como finalidad contribuir a un consumo activo y crítico de los medios de comunicación de masas y a la producción de mensajes propios. Se trata de dejar de ver a los medios como instrumento tecnológico y poner el énfasis en orientar la formación del estudiantado con respecto a los mismos. Siguiendo las definiciones y aportaciones de algunos teóricos destacados en esta materia (Aparici, 2008; Buckingham, 2005; Ferrés, 2008; Jenkins, 2008; Masterman, 1993; Pérez Tornero, 2000; Morduchowicz, 2009), nosotros consideramos que la Educación en Medios es aquella que: forma ciudadanas y ciudadanos críticos y autónomos; pretende desnaturalizar los medios, problematizándolos y cuestionándolos; reclama una nueva alfabetización acorde con los

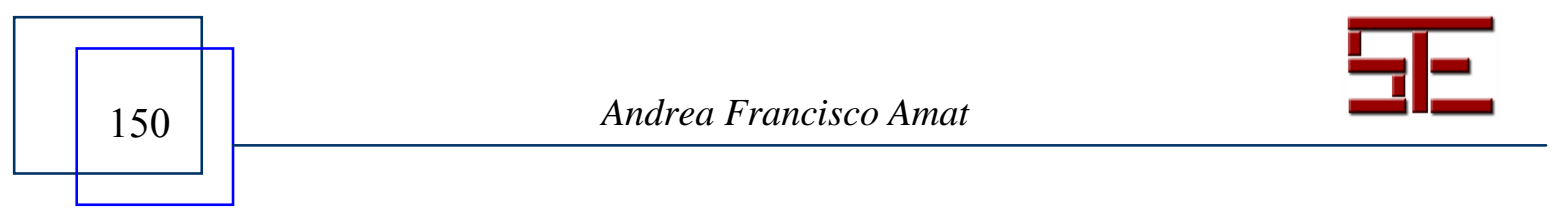




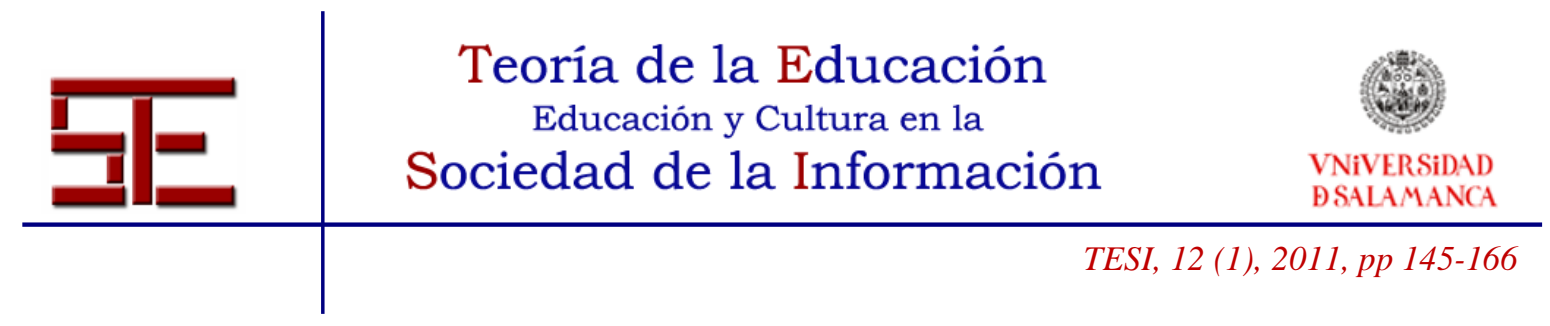

nuevos lenguajes; enseña a seleccionar, evaluar, contextualizar y asociar críticamente los mensajes de los medios de comunicación a las personas y enseña a utilizar creativamente los nuevos lenguajes para que las personas puedan producir sus propios mensajes. En definitiva, busca desarrollar la personalidad del estudiantado de forma integral, la formación de valores y el espíritu crítico. Sus acciones están orientadas a potenciar la competencia comunicativa que permita tanto leer los mensajes mediáticos como producir discursos alternativos e inclusivos. A continuación exponemos un esquema que, de manera sintética, presentan las principales características de los dos tipos de acciones: recepción y producción.

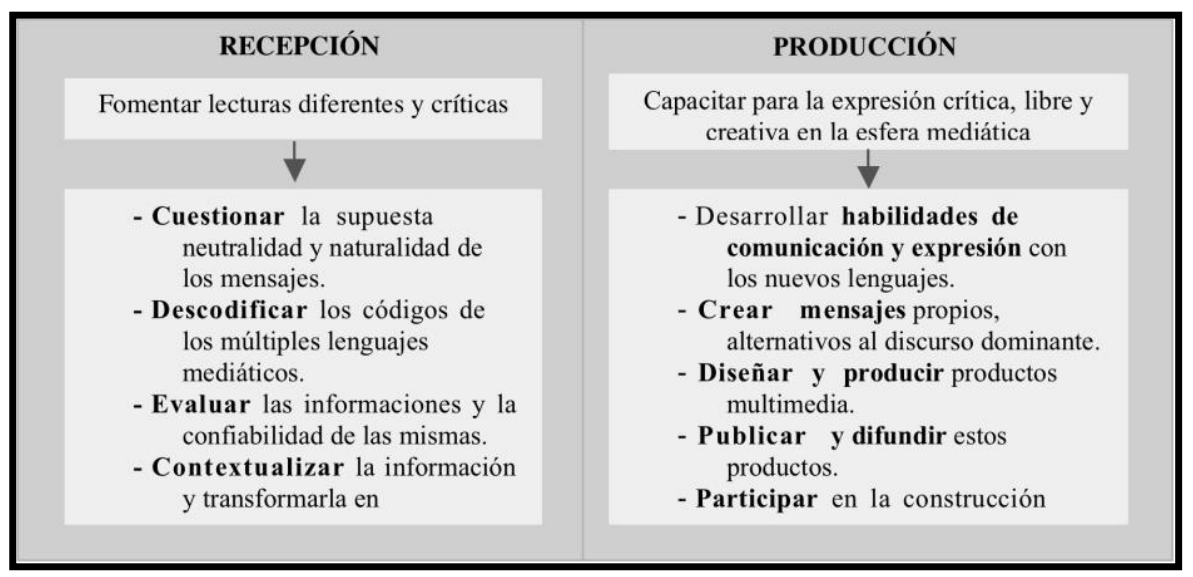

Esquemas 1. La Educación en Medios extraído de Francisco, 2009: 25

\subsection{Más allá del uso del ratón, el nuevo rol del docente}

Desde la década de los 90 del siglo $\mathrm{XX}$, se impuso la visión tecnologicista e instrumental a la hora de introducir los medios de comunicación en el aula. Los modelos eficientistas del Banco Mundial o el Fondo Monetario Internacional se extrapolaron también al ámbito de la educación y lo importante era dotar a los centros educativos de aulas de informática y enseñar al alumnado el manejo técnico de los ordenadores. (Aparici, 2003). Roszak recuerda que existe una distinción importantísima entre lo que hacen las máquinas cuando procesan información y lo que hace la mente cuando piensa. En un momento en que los ordenadores invaden las escuelas, es necesario que tanto maestros como estudiantes tengan presente esa distinción (Aparici, 1996).

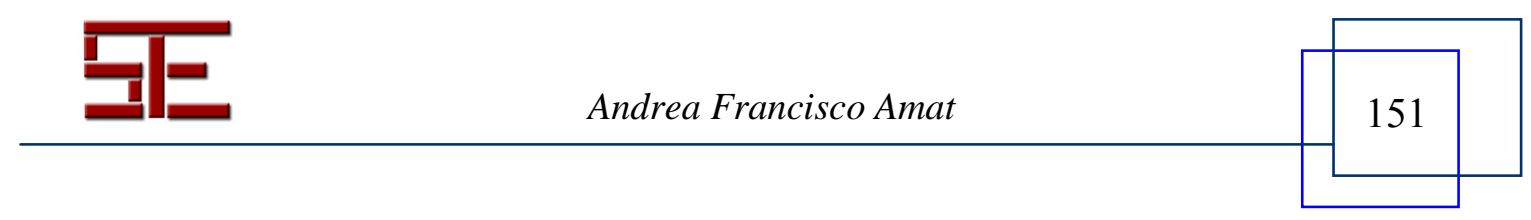




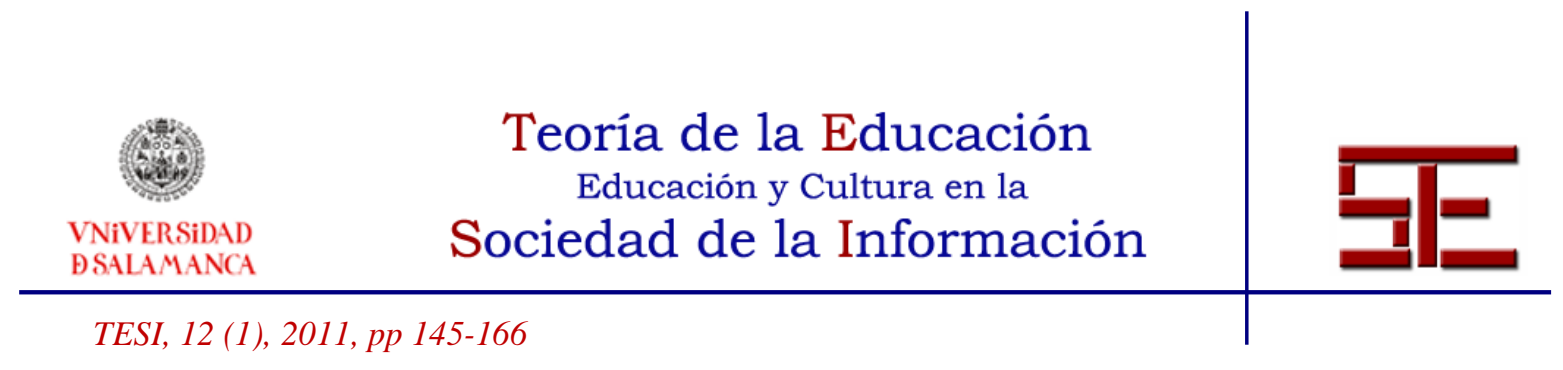

Como subraya la UNESCO (2008), disponer de computadores en los salones de clase no es suficiente de por sí para garantizar que los estudiantes puedan desarrollar las habilidades indispensables en el uso de las TIC que ellos necesitan para el trabajo y la vida diaria en el siglo XXI. Por eso, se han elaborado unos estándares de competencias que no se limitan a abordar las competencias en TIC, sino que van más allá y examinan dichas competencias a la luz de las novedades pedagógicas, de los planes de estudios, de la organización de las instituciones educativas y de las necesidades de los docentes que desean mejorar la calidad de su trabajo y la capacidad de colaborar con sus colegas.

En la educación superior hemos caído en la trampa de la subordinación de la pedagogía a la tecnología. (Rodríguez Izquierdo, 2010). Un aspecto a tener en cuenta en el futuro es que el solo uso de las TIC no es suficiente para marcar un cambio en el aprendizaje, sin tomar en consideración los diferentes factores que inciden sobre el individuo en una situación educativa. Como explica Rodríguez, ése es el gran reto que la enseñanza superior deberá asumir en la próxima década. Modificar el significado que tradicionalmente se ha atribuido a la docencia y lograr un giro del punto de gravedad: que de estar apoyado en la función "enseñanza" pase a hacerlo en la función "aprendizaje".

Y no solo se trata de ser competente en materia de TIC sino que el nuevo contexto europeo universitario exige una figura distinta de docente (Cabrero, López, Ballesteros, 2009). El profesor debe superar la función transmisora para aproximarse a la figura de facilitador de aprendizaje y permitir que la información se convierta en conocimiento. Debe adoptar una dimensión más dinámica como tutor, mediador, coordinador de equipos de trabajo y sistematizador de experiencias (Aguaded y Pérez Rodríguez, 2007; De Miguel, 2006; Zabala, 2006).). En este modelo de colaboración, los profesores "invitan" a sus estudiantes a definir los objetivos específicos dentro de la temática que se está enseñando, brindando opciones para actividades y tareas que logren atraer la atención de los alumnos, animando a los estudiantes a evaluar lo que han aprendido (Collazos, Guerrero y Vergara, 2001).

\subsection{La Web 2.0 como herramienta para el aprendizaje 2.0}

Con la aparición del software social o web 2.0, la red está transformándose de ser un gran medio, en el que la información era transmitida y consumida, a ser una plataforma en la que se crea contenido, se comparte y se reutiliza la información. No es solamente una revolución tecnológica, que abandera un conjunto de tecnologías que permiten

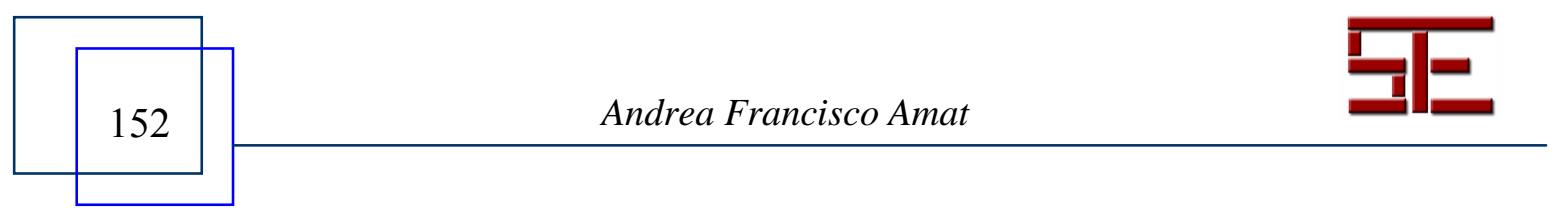




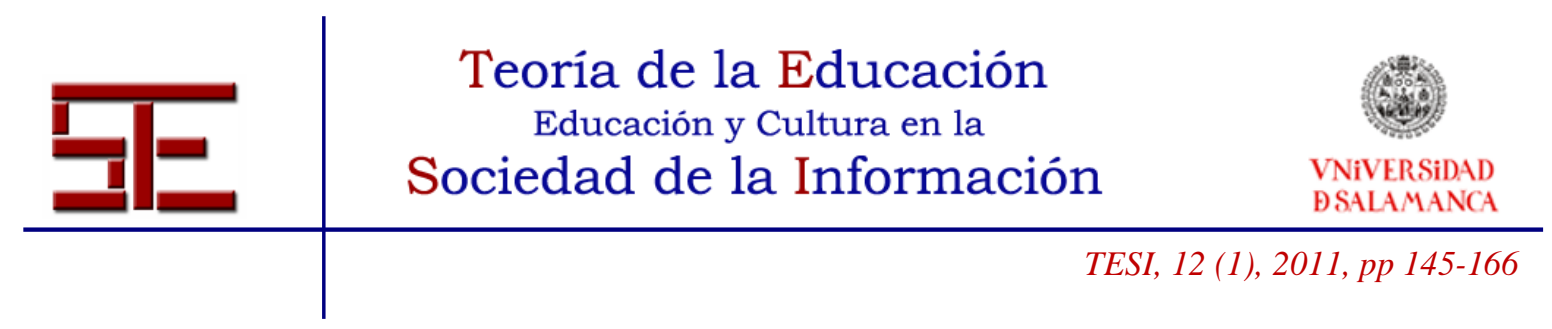

desarrollos web más interactivos, es más una actitud, una revolución social que busca una arquitectura de la participación a través de aplicaciones y servicios abiertos (Aguaded y López, 2009; O’Reilly, 2005; Downes, 2005). La web 2.0 consiste fundamentalmente en el cambio de papel del usuario de la red, que pasa de ser un mero lector a ser un lector- telespectador a escritor-realizador audiovisual (Ruiz, 2009).

El gran valor de la web 2.0 es reducir dramáticamente la distancia entre los que acceden a la web y los que publican en ella información. Actualmente cualquier usuario puede acceder, de forma gratuita, a un gestor de contenidos en la forma de un blog, publicar imágenes o vídeo. En este sentido, cabe destacar el abaratamiento de la producción y distribución de material escrito y audiovisual (Bartolomé, 2008). La web 2.0 ofrece nuevas funcionalidades que permiten hablar de Internet no sólo como gran fuente de recursos, sino, además, como la plataforma donde trabajar con esos recurso (Peña, Córcoles y Casado, 2006). Esto se traduce en dos acciones sustantivas del proceso de aprendizaje: generar contenidos y compartirlos.

Podría plantearse que este "Aprendizaje 2.0" se apoya en dos principios básicos de la actual Web: contenidos generados por el usuario y arquitectura de la participación. Cobo y Pardo (2007) señalan 4 formas de aprendizaje que este nuevo entorno permite:

- Aprender haciendo [learning-by- doing]: Para este tipo de aprendizaje resultan de especial utilidad aquellas herramientas que permiten al estudiante y/o docente la lectura y la escritura en la Web, bajo el principio de "ensayo-error". Por ejemplo, los estudiantes pueden aprender sobre ecología generando presentaciones en línea (de texto, audio o vídeo) sobre cómo se trata este tema en diferentes naciones del mundo. Luego el profesor lo revisa y corrige aquellos aspectos mejorables. Este proceso de creación individual y colectivo, a la vez, promueve un proceso de aprendizaje constructivista.

- Aprender interactuando [learning-by-interacting]: Una de las principales cualidades de las plataformas de gestión de contenidos es que además de estar escritas con hipervínculos, ofrecen la posibilidad de intercambiar ideas con el resto de los usuarios de Internet. Bajo este enfoque, el énfasis del aprender interactuando está puesto en la instancia comunicacional entre pares. Algunos ejemplos de interacción son: agregar un post en un blog o wiki, enviar un voice mail y actividades tan coloquiales como usar el chat, el correo electrónico o las redes sociales.

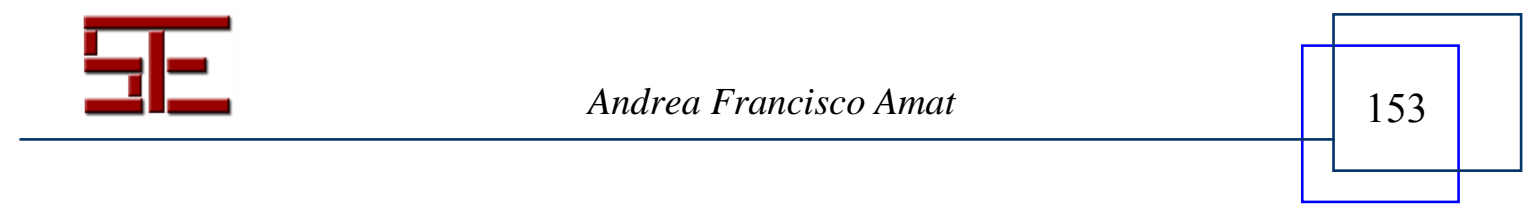




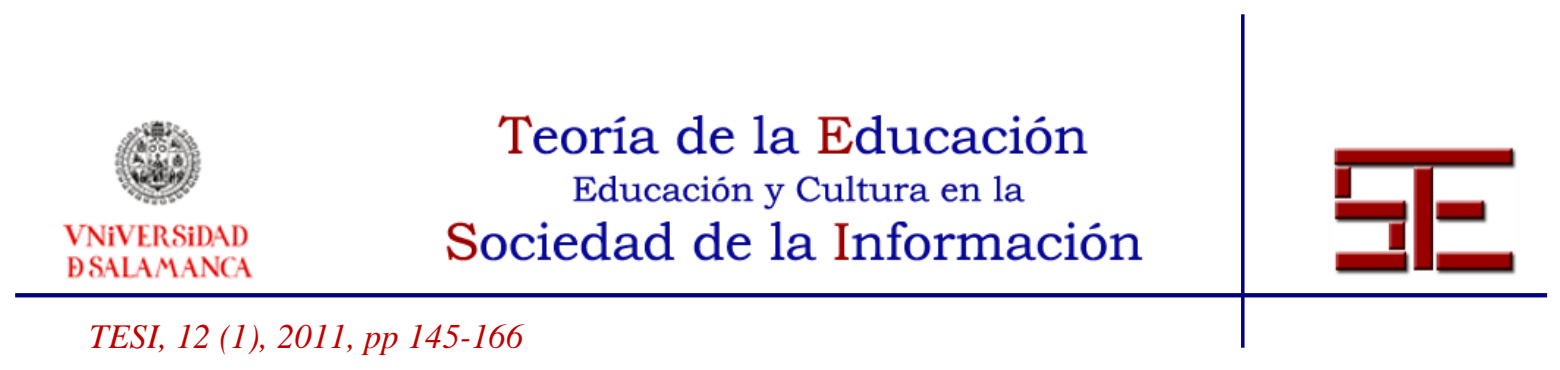

- Aprender buscando [learning-by-searching]: Uno de los ejercicios previos a la escritura de un paper, trabajo, ensayo o ejercicio, es la búsqueda de fuentes que ofrezcan información sobre el tema que se abordará. Ese proceso de investigación, selección y adaptación termina ampliando y enriqueciendo el conocimiento de quien lo realiza. En un entorno de gran cantidad de información disponible, resulta fundamental aprender cómo y dónde buscar contenidos educativos.

- Aprender compartiendo [learning-by-sharing]: El proceso de intercambio de conocimientos y experiencias permite a los educandos participar activamente de un aprendizaje colaborativo. Tener acceso a la información, no significa aprender: por esto, la creación de instancias que promuevan compartir objetos de aprendizaje contribuyen a enriquecer significativamente el proceso educativo. Internet cuenta con una gran cantidad de recursos para que los estudiantes puedan compartir los contenidos que han producido. Por ejemplo: plataformas para intercambio de diapositivas en línea, podcasts o videos educativos.

En este nuevo marco, el alumno ya no es un consumidor de contenidos, sino un "prosumidor": un consumidor y creador/productor de contenidos (Grané y Willen, 2009). Como destacan estos autores, una educación que no enseña estrategias para ser un ciudadano digital es una escuela que no educa para la sociedad de su tiempo. La alfabetización digital ha de ser considerada un método de indagación informada que promueve el uso crítico de las tecnologías tanto en la recepción como en la producción de contenidos a través de los medios digitales.

\section{USANDO LA WEB 2.0 PARA INFORMARSE E INFORMAR. UNA EXPERIENCIA EN EDUCACIÓN SUPERIOR}

\subsection{El proyecto}

Nuestra experiencia se está desarrollando desde el curso 2009-2010 en la Universidad Jaume I dentro del proyecto denominado "Experiencias de aprendizaje servicio con grupos interdisciplinares de educación y comunicación en temas de ciudadanía y cultura de paz" financiado por la Unidad de Apoyo Educativo de dicha institución. En este proyecto utilizamos el Aprendizaje Servicio (APS) $<1>$ como metodología de enseñanza-aprendizaje en el seno de tres asignaturas semestrales: Educación Cívica y Social, Discursos Audiovisuales y Cultura de Paz y Didáctica General, pertenecientes a

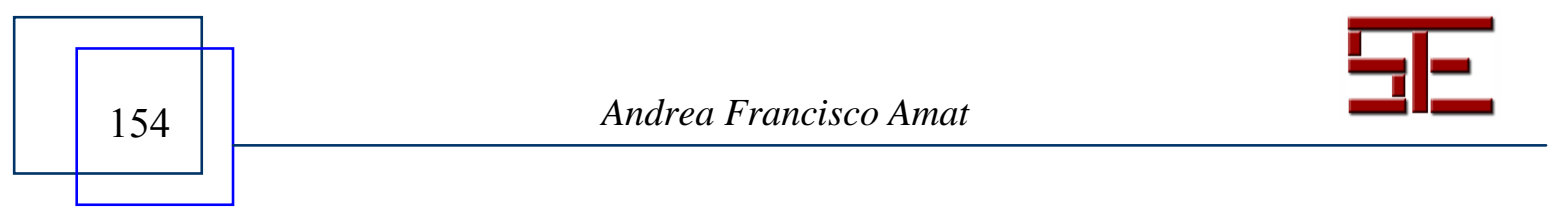




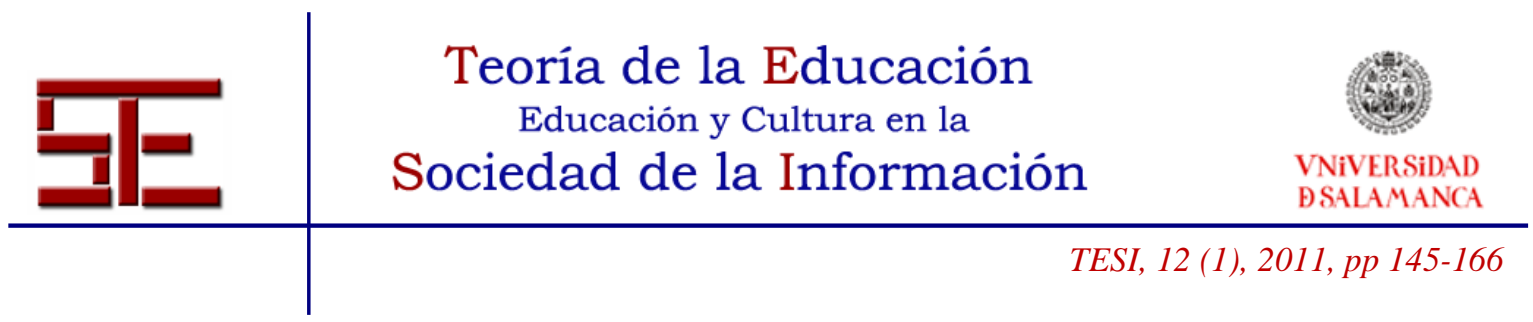

las titulaciones de Maestro, Comunicación Audiovisual y Psicopedagogía respectivamente.

El estudiantado elige un tema o valor y un ámbito donde prestar el servicio. Para la elaboración de todo el proyecto realizan los dos tipos de acciones básicas de la Educación en Medios: la lectura crítica y la producción propia de mensajes. Por una parte tienen que utilizar Internet para buscar información, por la otra tiene que usar las herramientas de comunicación disponibles, como las redes sociales y los blogs, para difundir información. De esta forma, aprenden haciendo, buscando, interactuando y colaborando (Cobo y Pardo, 2007).

Durante todo el semestre, el estudiantado desarrolla competencias básicas de la persona multialfabetizada (Area, 2010): habilidades para el acceso a la información y para el uso de cualquier recurso tecnológico, capacidades cognitivas para transformar la información en conocimiento y capacidades para la utilización de los lenguajes y formas de expresión para relacionarse y difundir la información a través de Internet.

Por motivos de extensión, en este artículo nos centraremos en el estudiantado de Educación Cívica del curso 2010/11. La materia es una asignatura optativa de 4 créditos del primer semestre. El estudiantado proviene de diversas facultades pero que en su mayor parte pertenecen al último curso de la diplomatura de magisterio en todas sus especialidades. La asignatura, de carácter teórico- práctico, busca iniciar un análisis sobre la sociedad actual y una reflexión sobre cómo potenciar valores ciudadanos necesarios para un desarrollo personal y social. Una acción que consideramos esencial si tenemos en cuenta el contexto en el que vivimos, donde se están produciendo cambios esenciales a un ritmo vertiginoso y sin tiempo para su reflexión. Un mundo de redes y canales de comunicación globales que están cambiando los límites del espacio público y privado y que afecta a nuestra forma de vivir y de convivir.

\subsection{Informarse e informar a través de la Web 2.0}

Como hemos comentado en el apartado anterior, el estudiantado realiza dos tipos de acciones relacionadas con la multialfabetización y la Educación en medios. Por una parte, la búsqueda, selección y análisis crítico de información. Por otra, la producción, difusión e intercambio de productos informativos elaborados con diferentes lenguajes y usando las TIC.

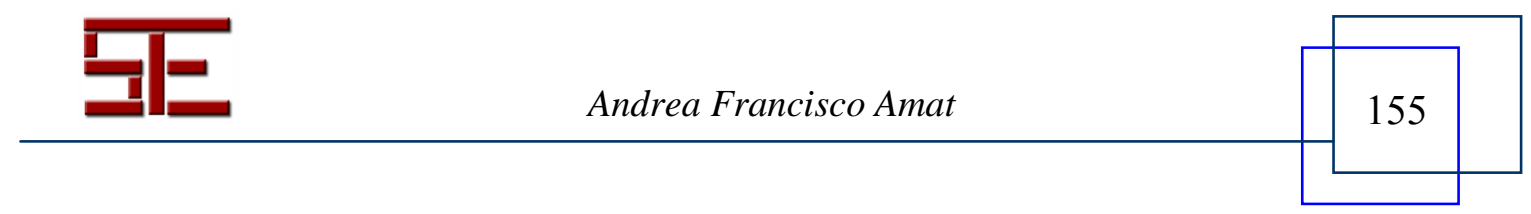




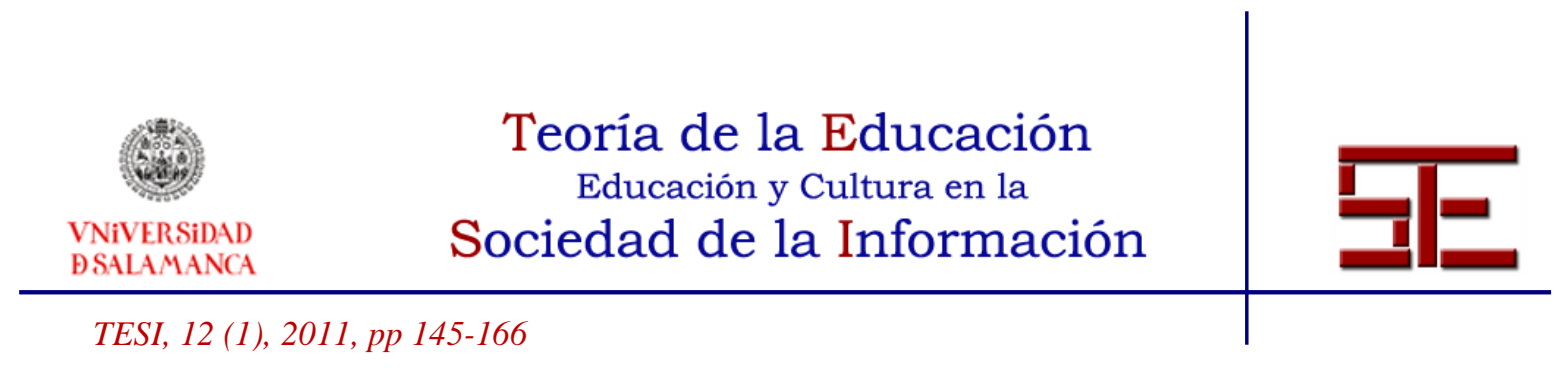

La lectura crítica comienza a trabajarse desde la primera fase, cuando los equipos de trabajo deben justificar la elección del tema o valor a trabajar y explicar los motivos por los cuales lo consideran relevante en el contexto actual. Para la realización de este marco teórico, utilizan la búsqueda, selección y análisis de información por Internet. La Red también les sirven para búsqueda de contactos con instituciones, organizaciones y colectivos con los que trabajar y para la elaboración del material que utilizan en sus intervenciones.

Entre los objetivos de esta actividad se encuentran: aprender a buscar información en la red; aprender estrategias de búsqueda en la red; conocer criterios relevantes en la selección de información; conocer criterios de confiabilidad de la información y de las fuentes informativas; realizar búsqueda de todo tipo de productor (textuales, sonoros, audiovisuales); aprender a analizar críticamente la información obtenida; aprender a relacionar la información obtenida, aprender a sintetizar la información. En esta parte del trabajo se desarrolla la capacidad de selección, análisis y síntesis de la información para elaborar un discurso propio.

El estudiantado, tras la elección del tema, la búsqueda, análisis y procesamiento de la información y el contacto con colectivos con los que desea trabajar, prepara el servicio a la comunidad que normalmente incluye una campaña de sensibilización sobre la temática y la elaboración propia de diversos materiales informativos (vídeos, carteles, folletos informativos,...) Para la realización de las campaña, la promoción de los eventos, la difusión de los vídeos realizados, ... utilizan tres herramientas destacadas de la web 2.0: los blogs, las redes sociales y los sitios de alojamiento de vídeo. Estas plataformas sirven para que el estudiantado difunda su información y sus producciones tanto textuales como audiovisuales.

Entre los objetivos de dicha actividad se encuentran: Contribuir a la alfabetización digital del estudiantado: aprender a crear y diseñar blogs; aprender a utilizar las redes sociales; aprender a editar vídeos; aprender a diseñar carteles y folletos informativos; facilitar espacios para que el estudiantado mejore sus competencias comunicativas escritas, audiovisuales y digitales; aprender a comunicar a través de diferentes lenguajes; promover una reflexión crítica sobre el uso de los blogs y las redes sociales; contribuir a la construcción del conocimiento colectivo de Internet con la aportación de información y de creaciones propias y promover la conciencia social y la participación ciudadana

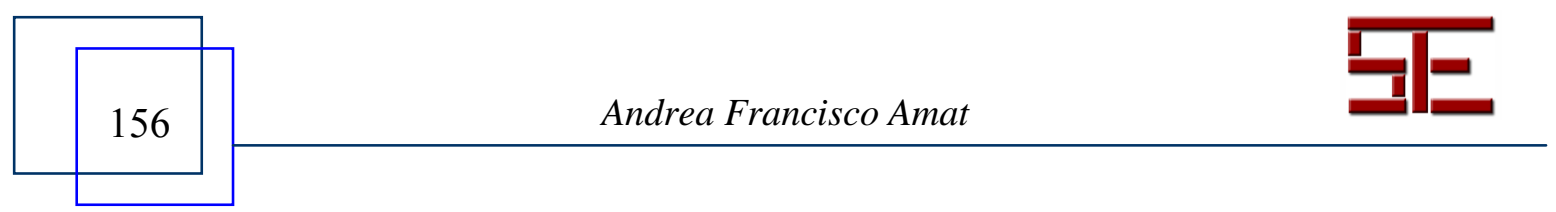




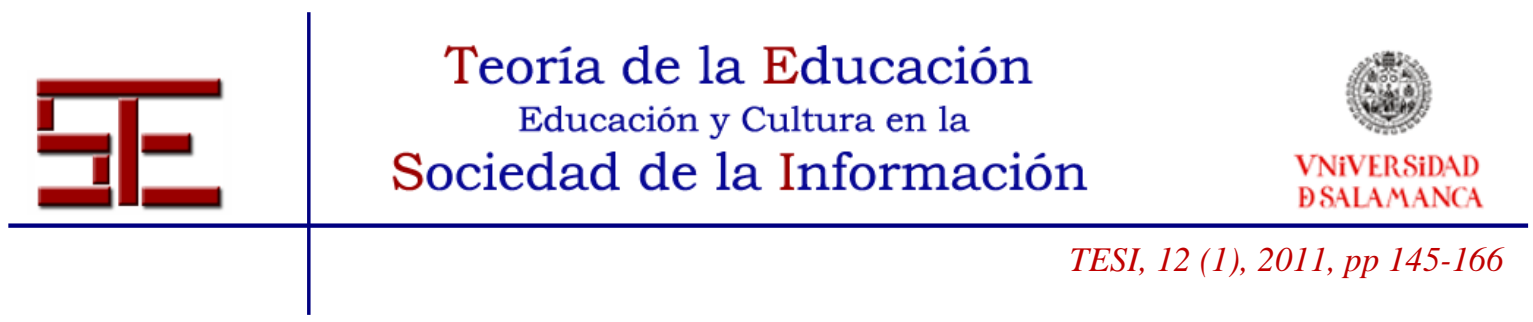

\subsection{Proyectos del estudiantado.}

Entre los trabajos que realizaron los estudiantes del curso 2010/2011, hemos optado en este apartado por explicar 3 como muestra representativa de la diversidad de enfoques que han dado a sus proyectos. Concretamente son las campañas "Eres lo que comes", "Una gran historia" y "Mantengamos la promesa" $<2>$.

El proyecto "Eres lo que comes: comida saludable" quería promocionar la alimentación saludable. Para ello, elaboraron una campaña con diversas acciones y entre ellas la creación de dos espacios virtuales: un blog y un perfil en la red social Facebook.

Varios eran los objetivos de estos espacios virtuales. El perfil en Facebook sirvió para promocionar la campaña y la actividad del Ágora, para que en la red social la gente se uniera a la causa y para difundir y visibilizar el blog. Mientas, el blog tenía como objetivo dar a conocer una serie de informaciones útiles para todas las personas interesadas en el tema. Para ello, la información se seleccionó y clasificó en diversas secciones: conocer otros alimentos, escuela de padres, recetario, sección de curiosidades, videos saludables (entre ellos, uno realizado por el propio grupo de estudiantes)

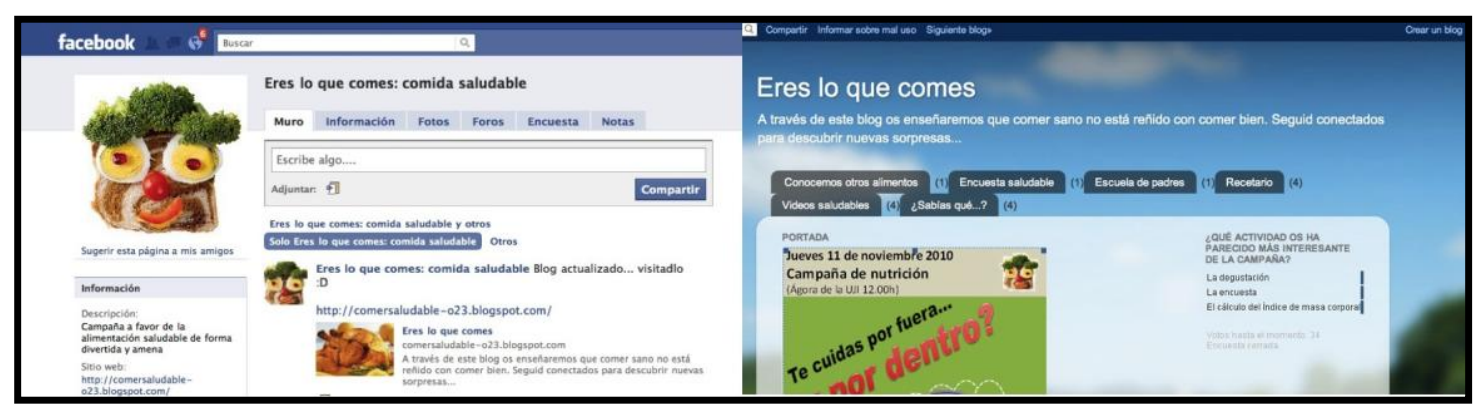

Imagen 1. Facebook y Blog de la campaña "Eres lo que comes"

Por otra parte, la campaña "Una gran historia" tenía como objetivo promocionar la Campaña Mundial de la Educación (CME). Para ello, el estudiantado accedió a la web de la $\mathrm{CME}$, se informó y revisó los materiales y las anteriores campañas y contacto con las $O N G$ 's responsables para proponerles participar en la campaña de 2011, cuyo tema es la exclusión de la mujer en el ámbito educativo. El resultado fue la producción de un vídeo que será utilizado por la CME; la creación de un perfil en Facebook para informar

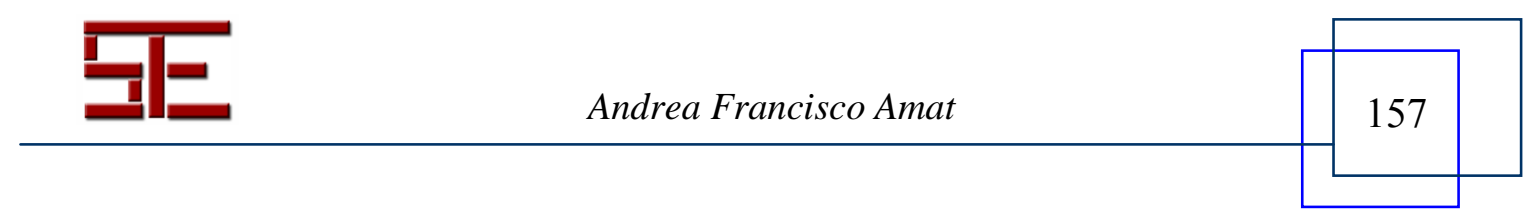




\begin{tabular}{c} 
Teoria de la Educación \\
Educación y Cultura en la \\
$\begin{array}{c}\text { VNiVERSIDAD } \\
\text { BSALAMANCA }\end{array}$ \\
\hline TESI, $12(1), 2011, p$ Pociedad de la Información
\end{tabular}

sobre la CME, difundir el vídeo y proponer a los internautas una actividad: elaborar historias sobre el derecho a la educación de las niñas y las mujeres.

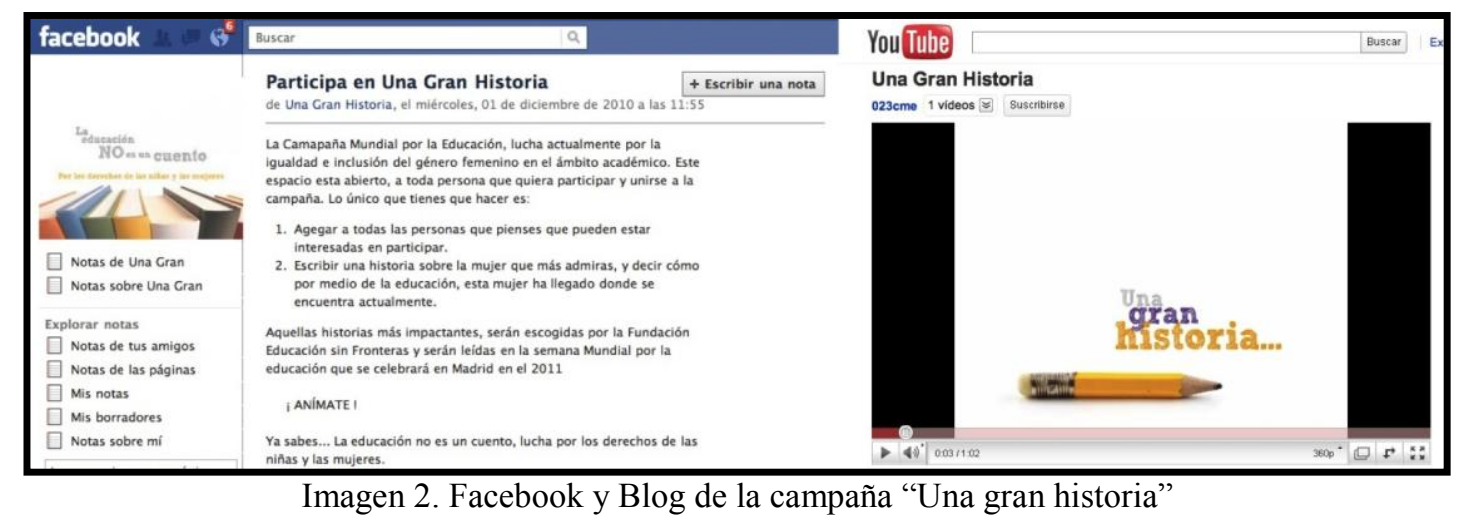

Con otro planteamiento, el trabajo "Mantengamos la promesa" se centraba en la promoción de los Objetivos de Desarrollo del Milenio. Recopilaron información, elaboraron una propuesta didáctica dirigida a alumnado de 4 de la ESO y lo aplicaron en un centro educativo. Para que la propuesta pudiera ser aprovechada por otros docentes, publicaron toda la información y el relato de su experiencia en un blog creado para esa finalidad.

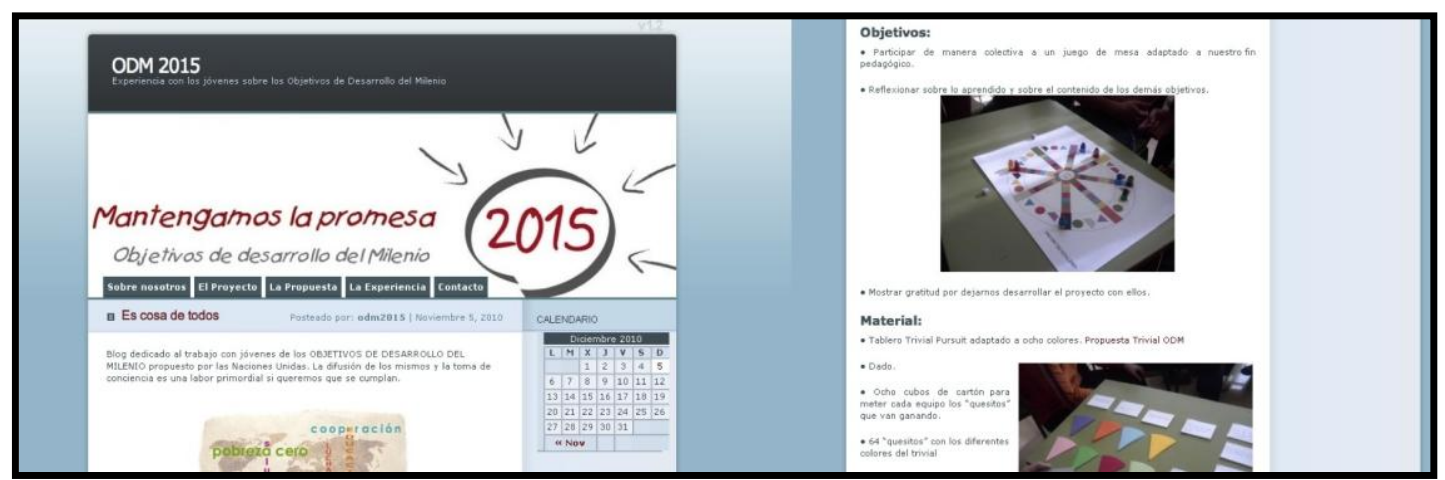

Imagen 3. Blog de la campaña "Mantengamos la promesa"

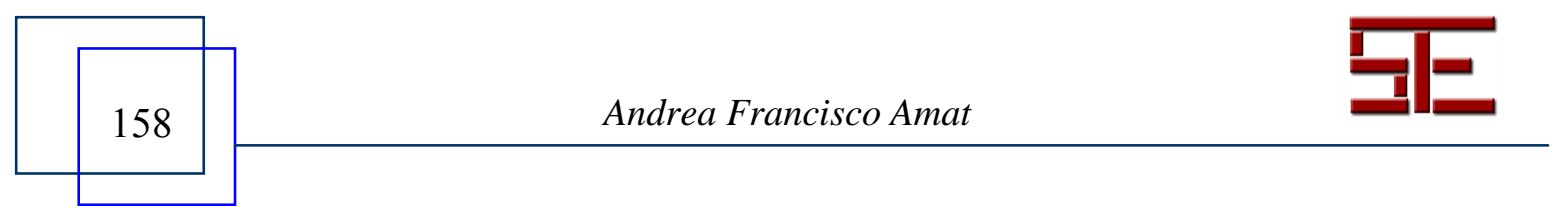




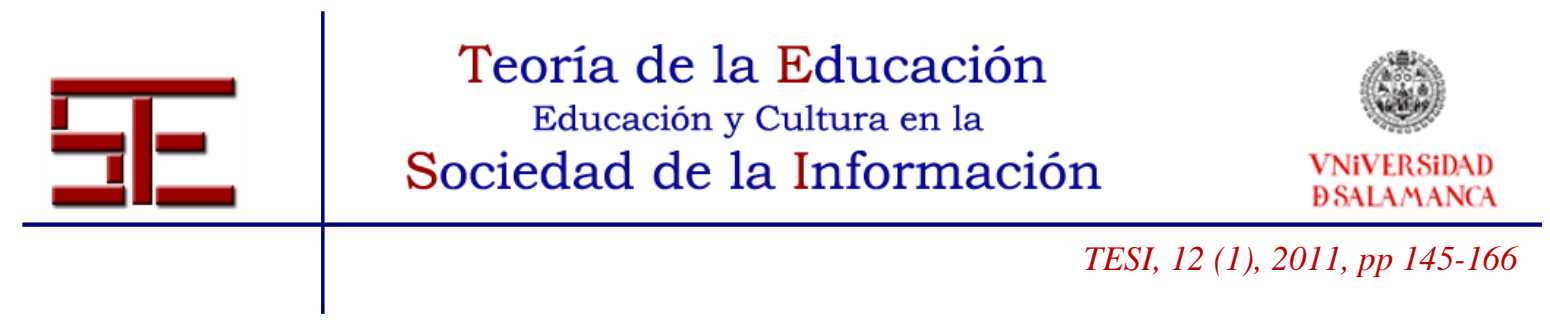

\subsection{La actitud del estudiantado ante la experiencia}

Para evaluar la actitud del estudiantado respecto a la experiencia y el aprendizaje producido por la introducción de las TIC y la alfabetización mediática en la asignatura, optamos por realizar un cuestionario de actitud tipo Likert. Dentro de los instrumentos de carácter cuantitativo empleados en la evaluación de actitudes, las escalas han sido las técnicas más importantes y de mayor aplicación. Consisten en proporcionar un cuestionario con una lista de enunciados (escalas clásicas de actitud) o con adjetivos bipolares (diferencial semántico) y solicitar que los encuestados respondan, de acuerdo con unos grados, según sus sentimientos o actitudes. Las escalas de actitudes permiten inferir las actitudes a partir de las respuestas que los sujetos dan ante una serie de frases o adjetivos. En el caso particular de las escalas de actitudes tipo Likert, el sujeto debe valorar su grado de acuerdo o desacuerdo ante un conjunto de declaraciones en forma de enunciado, que reflejan sus opiniones -actitudes verbalizadas- sobre el tema objeto de la medida, entre cinco o más grados, representados numéricamente (Morales, 1984).

El cuestionario se dividía en 7 temas y el estudiantado debía responder, del 1 al 5, si estaba muy en desacuerdo, en desacuerdo, no tenía clara su opinión, de acuerdo o muy de acuerdo, respectivamente, con las afirmaciones que se planteaban. Para una parte del cuestionario, la que hacía referencia a la introducción de las TIC en la asignatura, se realizó una adaptación de los items que habían emergido en un investigación cualitativa sobre la temática (Cabero, López y Ballesteros, 2009). Para la otra parte, se redactaron los items a partir de los principales objetivos pedagógicos relacionados con las TIC y la alfabetización mediática: la búsqueda y selección de información, la construcción de discursos mediante todo tipo de lenguajes y la propia alfabetización mediática.

\begin{tabular}{|l|l|}
\hline 1 & Las TIC son un recurso muy importante para la educación \\
\hline 2 & Las TIC potencian la motivación \\
\hline 3 & Las TIC son un aspecto fundamental en la formación del profesorado \\
\hline 4 & $\begin{array}{l}\text { Con el planteamiento de la asignatura hemos aprendido a buscar } \\
\text { información }\end{array}$ \\
\hline 5 & $\begin{array}{l}\text { Con el planteamiento de la asignatura hemos aprendido a seleccionar } \\
\text { información }\end{array}$ \\
\hline 6 & $\begin{array}{l}\text { Con el planteamiento de la asignatura hemos aprendido a comunicar } \\
\text { a través de diferentes lenguajes }\end{array}$ \\
\hline 7 & \begin{tabular}{l} 
Con el planteamiento de la asignatura nos hemos alfabetizado digital \\
\hline
\end{tabular} \\
\hline
\end{tabular}

Tabla 1. Los temas del cuestionario

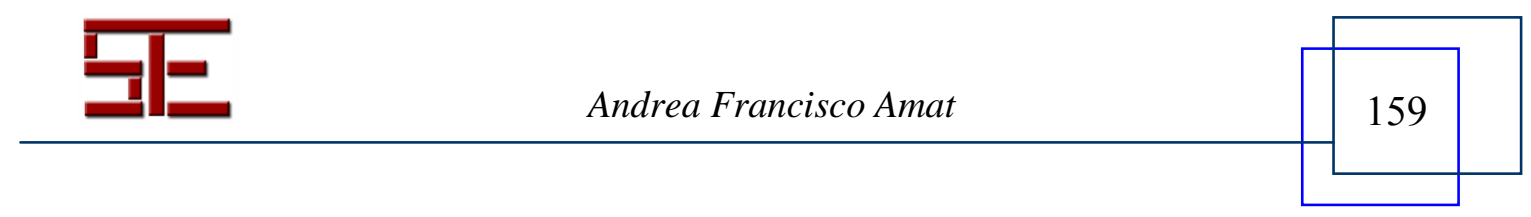




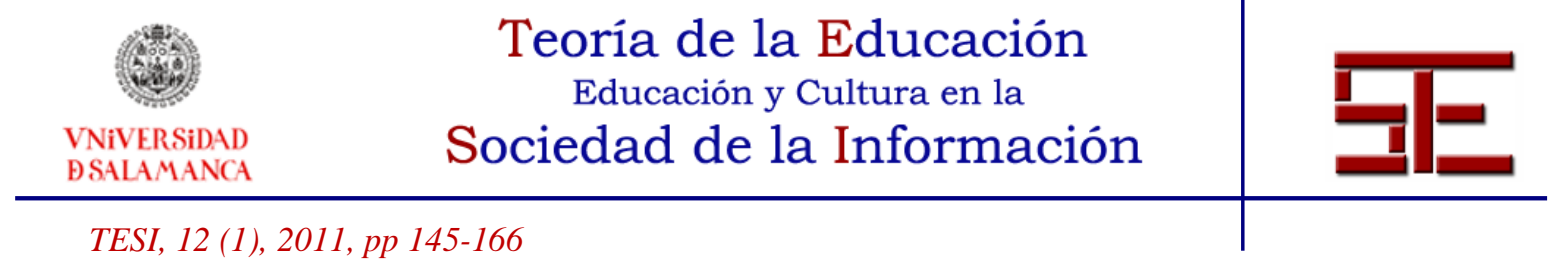

El cuestionario fue respondido por 31 estudiantes de Educación Cívica, lo que representaba el $77 \%$ del estudiantado que estaba matriculado en este itinerario. En este sentido, cabe indicar que la participación fue elevada teniendo en cuenta que era de carácter voluntario y no entraban como criterio de evaluación, y parte del estudiantado opta por un itinerario no presencial.

Los resultados mostraron una actitud positiva por parte del estudiantado hacia la experiencia y el aprendizaje producido en materia de TIC y alfabetización mediática. A continuación presentamos las puntuaciones obtenidas en la escala agrupados por estas dos temáticas: la introducción de las TIC y los aprendizajes producidos en la asignatura.

Como podemos observar en la gráfica 1, la cual hace referencia a los ítems sobre la introducción de las TIC en la asignatura de Educación Cívica, todos los estudiantes consideraron que las TIC son un recurso muy importante par la educación, el 94\% opinaba que potencian la motivación y el $87 \%$ que son un recurso fundamental en la formación de los docentes.

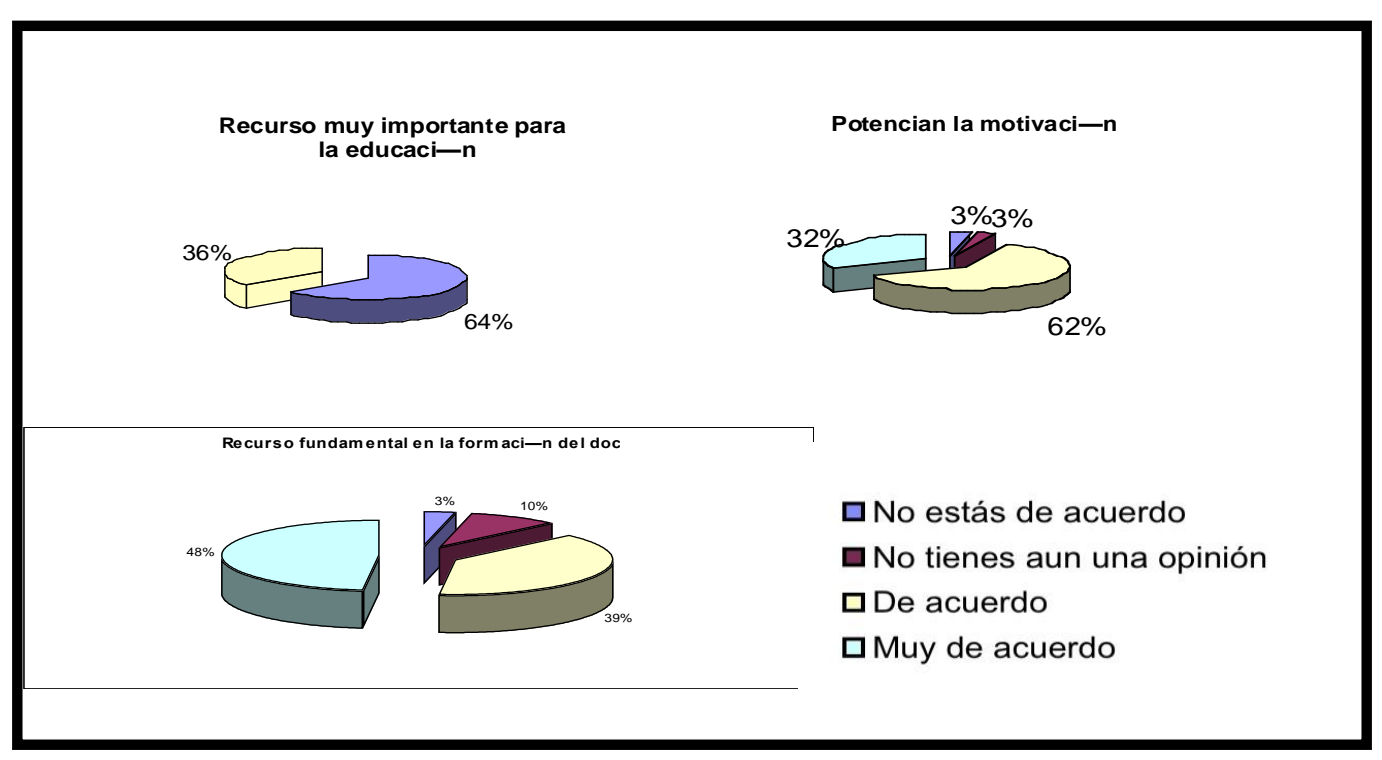

Gráfica 1. Resultados del cuestionario respecto a la introducción de las TIC en la asignatura

En el bloque dos, relativo a los ítems sobre la valoración del aprendizaje en la asignatura, las respuestas fueron igualmente positivas. Como podemos observar en la gráfica 2, el estudiantado afirmó que con el planteamiento de la asignatura había

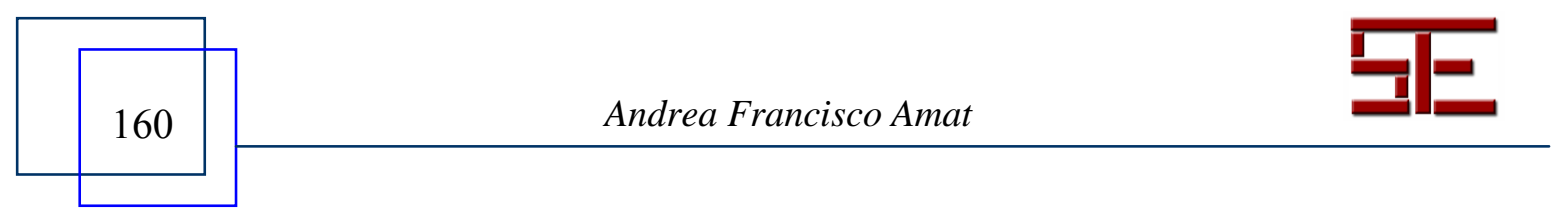




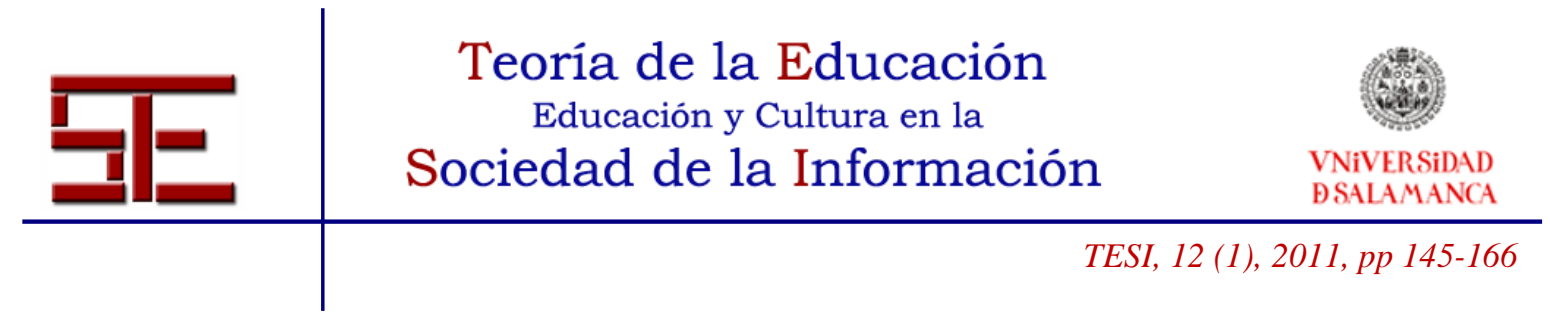

aprendido a buscar (75\%) y seleccionar información (80\%) y a comunicar a través de diferentes lenguajes (90\%). Además, consideraban que se habían alfabetizado digitalmente $(74 \%)$.

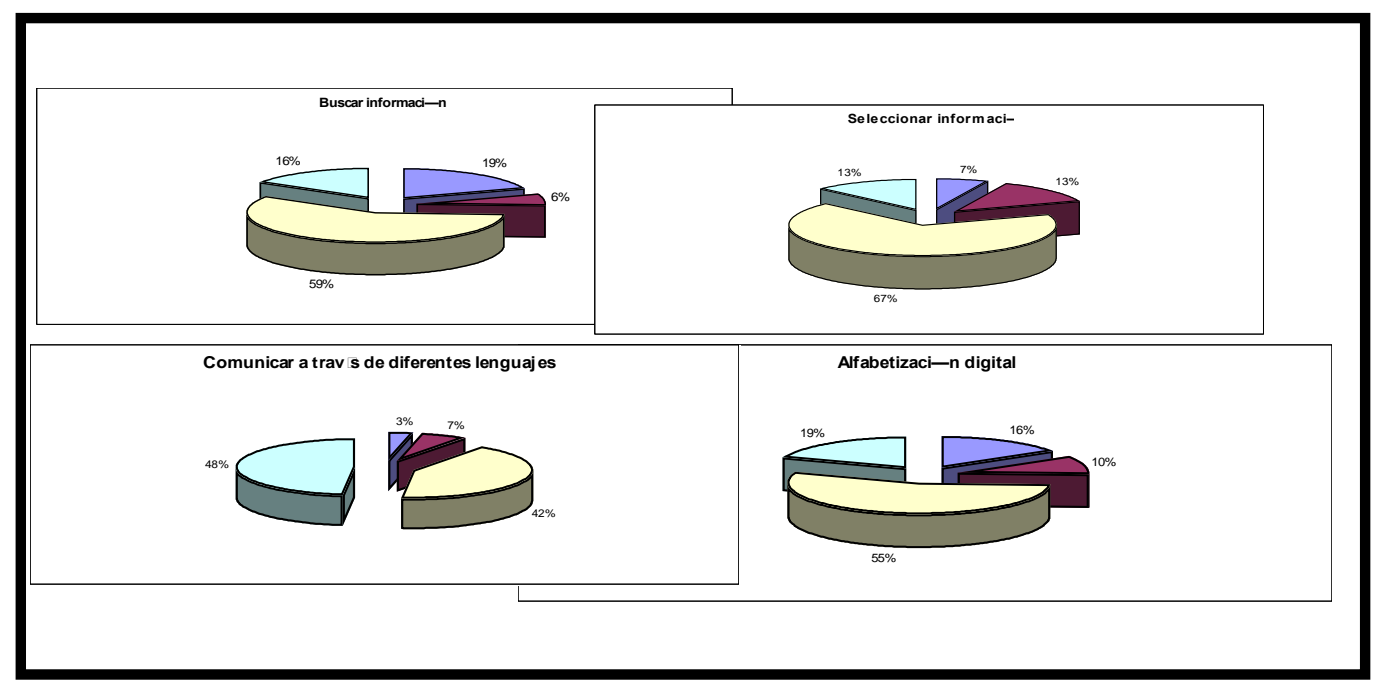

Gráfica 2. Resultados del cuestionario respecto a los aprendizajes producidos por la asignatura

Estos resultados muestran una alta valoración tanto de la introducción de las TIC en la asignatura como del aprendizaje producido por el planteamiento de trabajo. Estas puntuaciones están en estrecha relación con la motivación y la implicación del estudiantado en la asignatura y en sus proyectos. De hecho, los grupos que optaron por este itinerario realizaron trabajos que superaban las exigencias académicas, se lo tomaron como proyectos personales que iban más allá de la superación de una asignatura y esto mejoró el proceso de aprendizaje, convirtiéndolo en un aprendizaje significativo.

\section{CONCLUSIONES}

Vivimos en la sociedad de la información, en un espacio saturado de mensajes mediáticos donde las pantallas y el tiempo dedicado a su consumo crecen a un ritmo vertiginoso. Si queremos pasar de la información al conocimiento es necesario desarrollar una serie de competencias relacionadas con la multiafabetización, la lectura crítica (búsqueda, selección, análisis, procesamiento de la información) y la producción de mensajes mediáticos propios (utilizando diferentes lenguajes y canales).

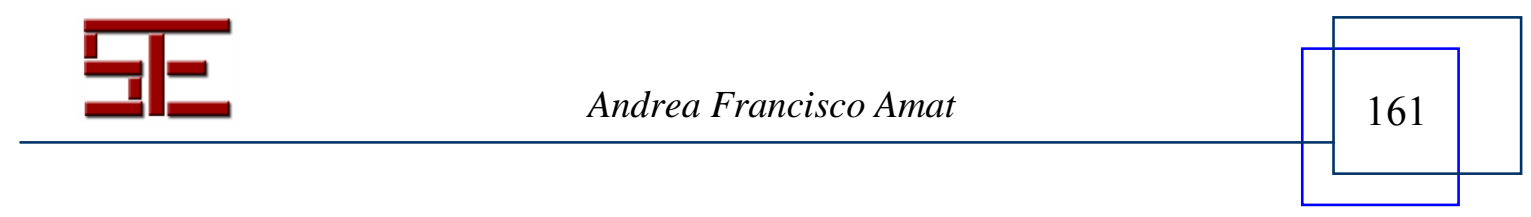




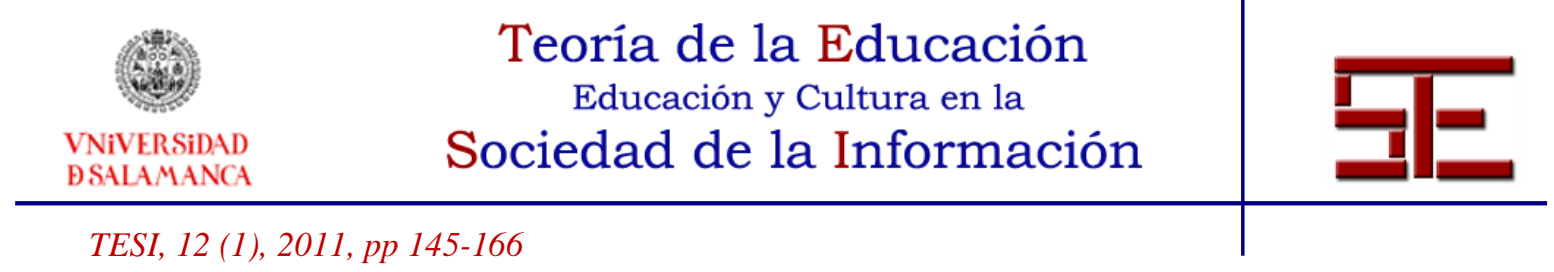

En este contexto, el nuevo rol del docente es el de guía o facilitador de espacios de aprendizaje que permitan al estudiantado adquirir las competencias necesarias para enfrentarse a los retos del siglo XXI y entre ellas es necesario que se encuentre la multialfabetización.

La red es una herramienta para esas habilidades de lectura y producción de información. Concretamente, la Web 2.0 ofrece la posibilidad no sólo de educar en la búsqueda, selección y análisis de la información sino en la producción y difusión de información propia. Experiencias como las relatadas en este artículo nos muestran sus posibilidades pedagógicas y las repercusiones en el aprendizaje del estudiantado. De esta forma, aprenden haciendo, buscando, interactuando y colaborando (Cobo y Pardo, 2007).

\section{BIBLIOGRAFÍA}

Acaso, M. (2006) Esto no son las Torres Gemelas. Cómo aprender a leer la televisión y otras imágenes. Madrid: La Catarata

Aguaded, J.I. y López, E. (2009). La blogsfera educativa: nuevos espacios universitarios de innovación y formación del profesorado en el contexto europeo. Revista Interuniversitaria de Formación del Profesorado (pp 165-172) 12 (3). Extraído el 15 de octubre,2010, de http://www.aufop.com/aufop/uploaded_files/articulos/1254437860.pdf

Aguaded, J.I. y Pérez Rodríguez, M. (2007). La educación en medios de comunicación como contexto educativo en un mundo globalizador. En Cabero, J. (coord.). Nuevas tecnologías aplicadas a la educación (pp 63-75). Madrid: McGraw-Hill.

Aparici, R. Coord. (1996) La revolución de los medios audiovisuales. Educación y nuevas tecnologías. Madrid: Ediciones La Torre.

Aparici, R. Coord. (2003). Comunicación educativa en la sociedad de la información. Madrid: UNED

Aparici, R. y García Mantilla, A. (2008). Lectura de imágenes en la era digital. Madrid: Ediciones La Torre

Aranda, D.; Sánchez-Navarro, J. y Tabernero, C (2009). Jóvenes y ocio digital. Informe sobre el uso de herramientas digitales por parte de adolescentes en España. Barcelona:

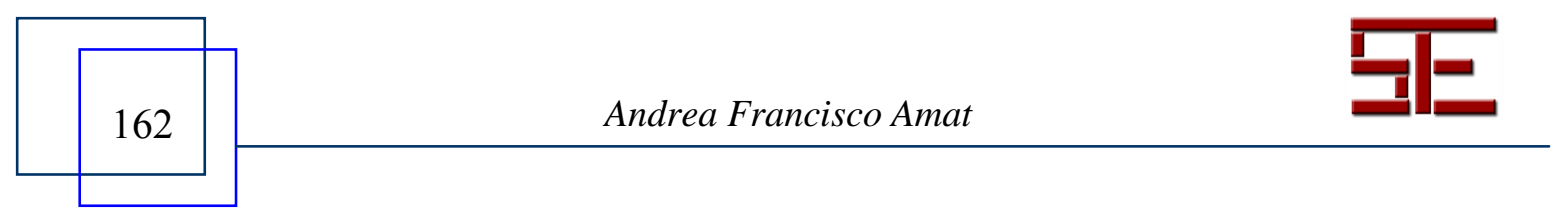




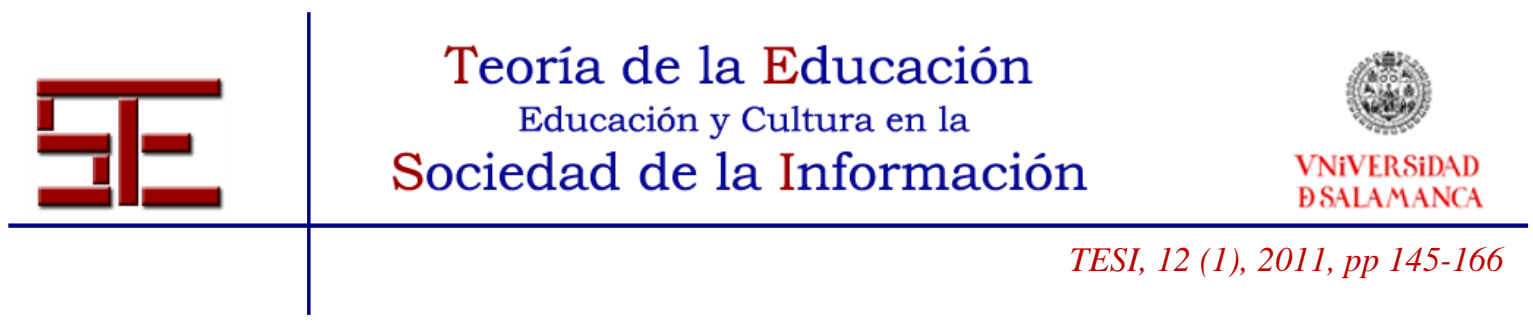

\section{Editorial UOC}

Area, M.; Gros, B. y Marzal, M.A. (2008). Alfabetizaciones y tecnologías de la información y la comunicación. Madrid: Síntesis.

Area, M. (2010a). ¿Por qué formar en competencias informacionales y digitales en la educación superior? Revista de Universidad y Sociedad del Conocimiento (RUSC). Vol. 7, n.o 2. UOC. Extraído el 25 de noviembre, 2010, de http://rusc.uoc.edu/ojs/index.php/rusc/article/view/v7n2-area/v7n2-area

- (2010b). Multialfabetización, ciudadanía y cultura digital: redefinir la escuela del siglo xxi. Novedades educativas (pp 4-7). Núm. 231, marzo.

Barómetro comunicación (2010). Informe la dieta mediàtica i cultural dels joves. Extraído el 1 de diciembre, 2010, de http://www.fundacc.org/docroot/fundacc/pdf/dieta_mediatica_i_cultural_joves_2010.pd f.

Bartolomé, A. (2008). Web 2.0 and New Learning Paradigms. eLearning Papers No 8. Extraído el 20 de abril, 2010, en www.elearningpapers.eu.

Bauman, Z. (2007). Vida de consumo. Madrid: Fondo de Cultura Económica.

British Library \& JISC (2008). Information behaviour of the researcher of the future. Informe Generación Google. Extraído el 13 de marzo, 2009, de http://www.eduteka.org/pdfdir/GoogleGeneration.pdf

Buckingham, D. (2005). Educación en medios. Alfabetización, aprendizaje y cultura contemporánea. Barcelona: Paidós.

Cabero, J.; López, E. y Ballesteros, C. (2009). Experiencias universitarias innovadoras con blogs para la mejora de la praxis educativa en el contexto europeo. Revista de Universidad y Sociedad del Conocimiento (RUSC). Vol. 6, n.o 2. UOC. Extraído el 15 de octubre, 2010, de http://www.raco.cat/index.php/RUSC/article/view/140242/191428

Castells, M. (2001). La era de la información. Vol. 1. La sociedad red. Madrid: Alianza Ed.

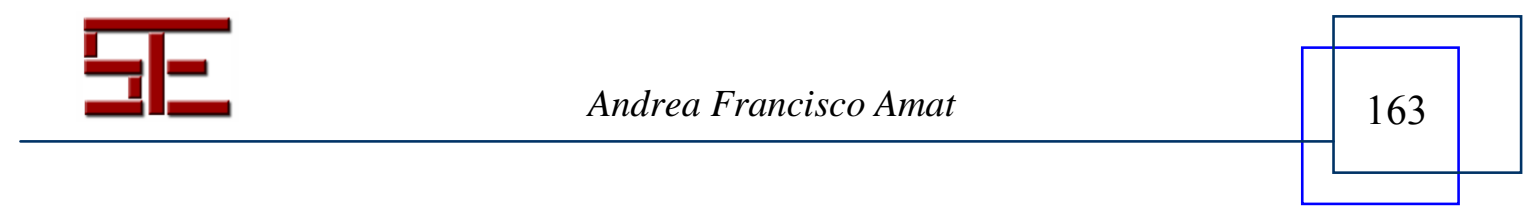




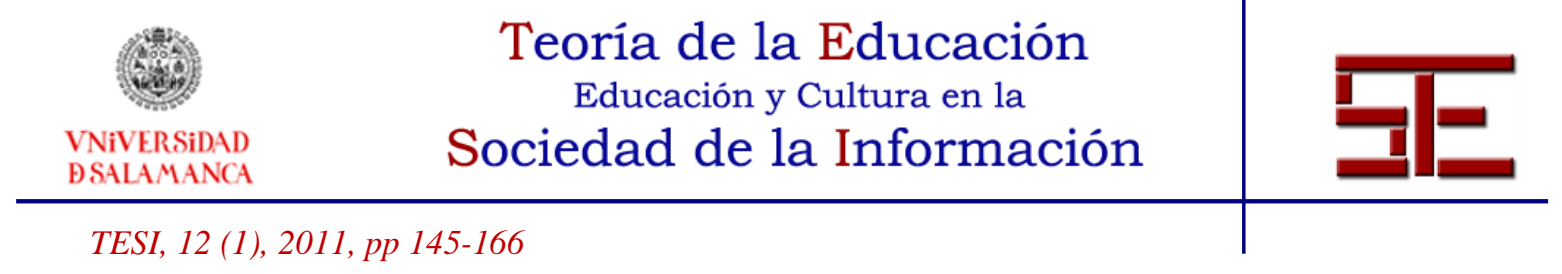

Cobo, C. y Pardo, H. (2007). Planeta Web 2.0. Inteligencia colectiva o medios fast food. Barcelona / México DF: Grup de Recerca d'Interaccions Digitals, Universitat de Vic. Flacso México.

Collazos, C.A.; Guerrero, L. y Vergara, A. (2001). Aprendizaje Colaborativo: un cambio en el rol del profesor. Memorias del III Congreso de Educación Superior en Computación, Jornadas Chilenas de la Computación, Punta Arenas, Chile. Extraída el 29 de enero, 2009, de http://www.dcc.uchile.cl/ luguerre/papers/CESC-01.pdf

De Miguel, M. (2006). Metodologías para optimizar el aprendizaje: segundo objetivo del Espacio Europeo de Educación Superior. Revista interuniversitaria de formación del profesorado (pp. 71-92). 57.

Díaz Nosty, B. (1996). La Sociedad de la Información. Amenazas y oportunidades. Madrid: Editorial Complutense.

Downes, S. (2005): E-learning 2.0. Elearn Magazine. Extraído el 6 de diciembre, 2007, en www.elearnmag.org

Ferrés, J. (2008). La educación como industria del deseo: un nuevo estilo comunicativo. Barcelona: Gedisa

Francisco, A. (2008). Educación para la participación: desarrollo de un currículum alternativo en la ESO sobre ciudadanía y medios de comunicación. Universidad Autónoma de Barcelona. ISBN: B-44131-2008/978-84-691-6569-0. (http://www.tesisenred.net/TDX-0202109-162938).

- (2009) Medios para la participación. Lectura crítica y producción mediática ciudadana. Novadors Edicions. Col.lecció INVESTIC, no 2. Faura, Valencia.

FUENTES, M. (2001). Naufragar en Internet. Estrategias de búsqueda de información en redes telemáticas. Virtual Educa, Madrid, 27-29 de junio de 2001. [Publicada por la UOC (http://www.uoc.edu/web/esp/art/uoc/01090 37/fuentes.html\#bibliografia )].

GRANÉ, M., y WILLEN, C. (Eds.) (2009): Web 2.0: nuevas formas de aprender y participar. Barcelona: Laertes educación.

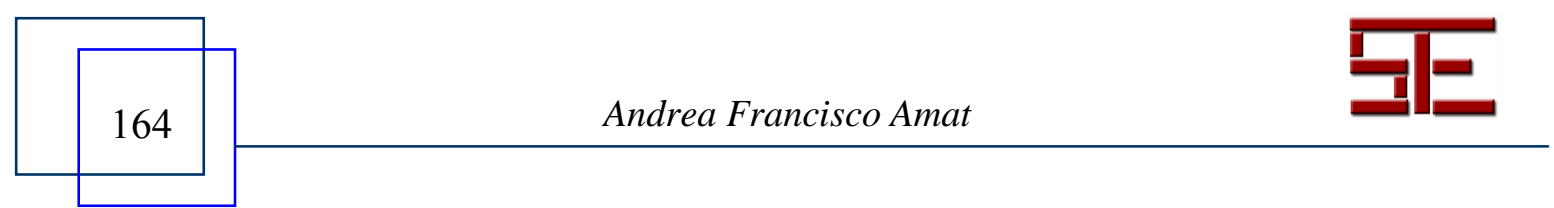




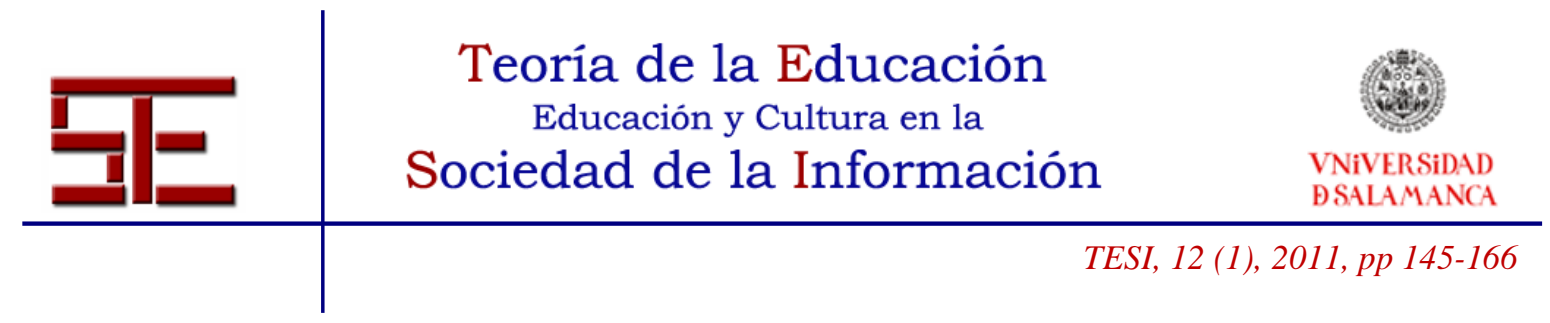

GITLIN, T. (2005). Enfermos de información. De cómo el torrente mediático está saturando nuestras vidas. Barcelona: Paidós.

Hernández-Serrano, M. J. (2009): Estrategias de búsqueda de información para la generación de conocimiento en la Red. Tesis doctoral. Salamanca: Ediciones Universidad de Salamanca.

Marta Lazo, Carmen (2007). La educación para el consumo de pantallas, como praxis holística. Revista Latina de Comunicación Social, 62. Extraída el 10 de marzo, 2009, en http://www.ull.es/publicaciones/latina/200720_Carmen_Marta_Lazo.htm

Jenkins, H. (2008). Convergence culture. La cultura de la convergencia de los medios de comunicación. Barcelona: Paidós.

Masterman, L. (1993). La enseñanza de los medios de comunicación. Madrid: Ediciones la Torre.

Morales, P. (1984). Medición de actitudes en psicología y educación. San Sebastián: Tártalo

Morduchowicz, R. (2009). Los jóvenes y las pantallas: nuevas formas de sociabilidad. Barcelona: Gedisa.

Nafria, I. (2008). Web 2.0. El usuario, el nuevo rey de Internet. Madrid: Ediciones Gestión.

O'Reilly, T. (2005): What is web 2.0. Design Patterns and Bussiness Models for the Next Generation of Software. Extraído el 15 de febrero de 2009 en www.oreillynet.com

Puig., J.M., y Palos., J. (2006). Rasgos pedagógicos del aprendizaje-servicio. Cuadernos de Pedagogía (pp. 60-63). 357.

Peña, I.; Córcoles, C. P. y Casado, C. (2006). El Profesor 2.0: docencia e investigación desde la Red. UOC Papers N.o 3. UOC. Extraído el 23 de julio, 2009, en http://www.uoc.edu/uocpapers/3/dt/esp/pena_corcoles_casado.pdf

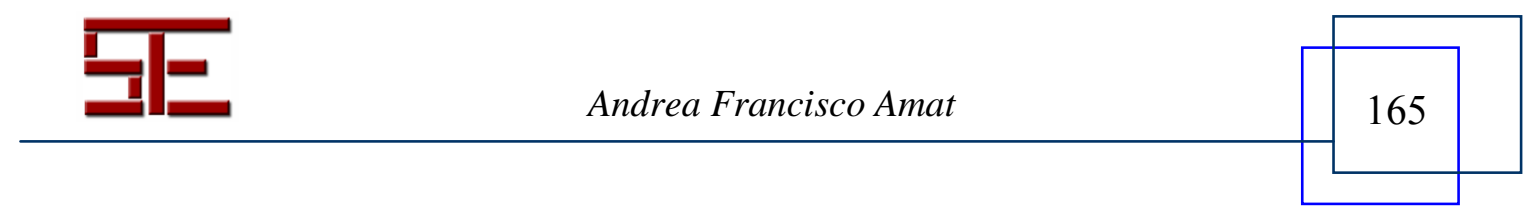




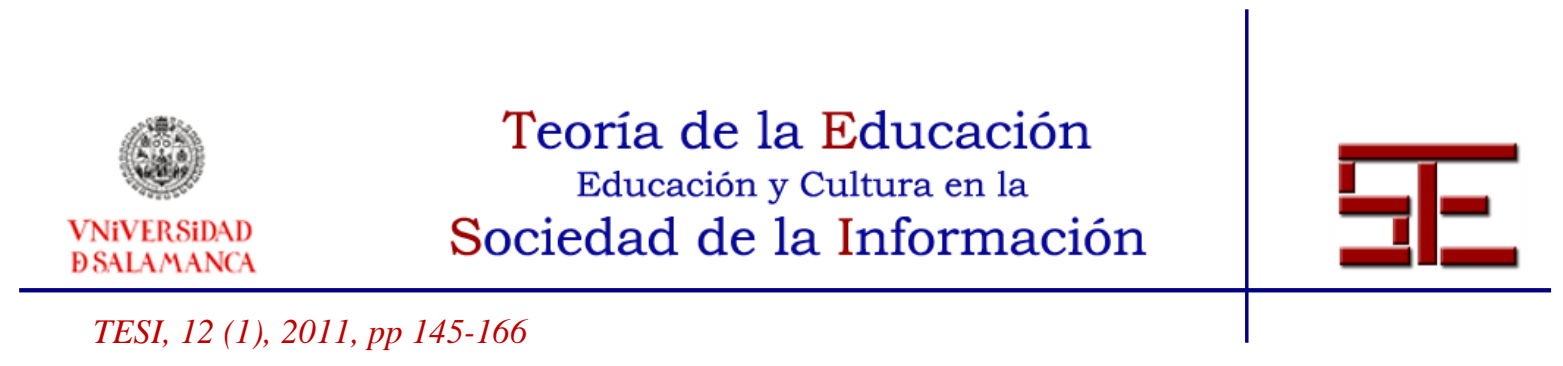

Pérez Tornero, J.M. (2000). Comunicación y educación en la sociedad de la información. Barcelona: Paidós

Ramonet, I. (2000). La tiranía de la comunicación. Barcelona: Temas de debate.

Rodríguez Izquierdo, R. M. (2010). El impacto de las TIC en la transformación de la enseñanza universitaria: repensar los modelos de enseñanza y aprendizaje. En De Pablos Pons, J. (Coord.) Buenas prácticas de enseñanza con TIC. Revista Electrónica Teoría de la Educación: Educación y Cultura en la Sociedad de la Información. (pp. 32-68) Vol. 11, no 1. Universidad de Salamanca, pp. 32-68. Extraído el 1 de diciembre, 2010, en http://revistatesi.usal.es/ revistas_trabajo/index.php/revistatesi/article/view/ http://campus.usal.es/ revistas_trabajo/index.php/revistatesi/article/view/5788/5818

Ruiz, F.J. (2009). Web 2.0. Un nuevo entorno de aprendizaje en la Red. Revista Didáctica, Innovación y Multimedia. 5,13. Extraído el 10 de enero, 2010, en www.pangea.org/dim/revistaDIM13/Articulos/pacoruiz.pdf

UNESCO (2008): Estándares de competencia en TIC para docentes. Extraído el 28 de septiembre, 2009, en http://www.eduteka.org/EstandaresDocentesUnesco.php

VVAA. (2008). Informe 2008 Juventud en España. Madrid: INJUVE,

Zabala, M. A. (2006). La convergencia como oportunidad para mejorar la docencia universitaria. Revista interuniversitaria de formación del profesorado (pp. 37-70) 57.

Notas:

$<1>$ Nota 1: El APS es una propuesta educativa que combina procesos de aprendizaje y de servicio a la comunidad en un solo proyecto bien articulado en el que los participantes se forman al trabajar sobre necesidades reales del entorno con el objetivo de mejorarlo. Para más información consultar Puig y Palos, 2006.

$<2>$ Nota 2: El proyecto "Eres lo que comes" fue elaborado por los estudiantes: Lucía Agut, Elisa Badenes, Pablo Granada, Laia Grau y Sonia Moreno. El proyecto "Una gran historia" fue elaborado por Irene De Juan, Neu Herrera, Mariana Ibarra y Manoli Morales. El proyecto "Mantengamos la promesa" fue elaborado por Ismael Cabello, Sandra Carcas, Honorato Ginés, Carlos Sanz, Jonatan Sierra y Aitor Rubio.

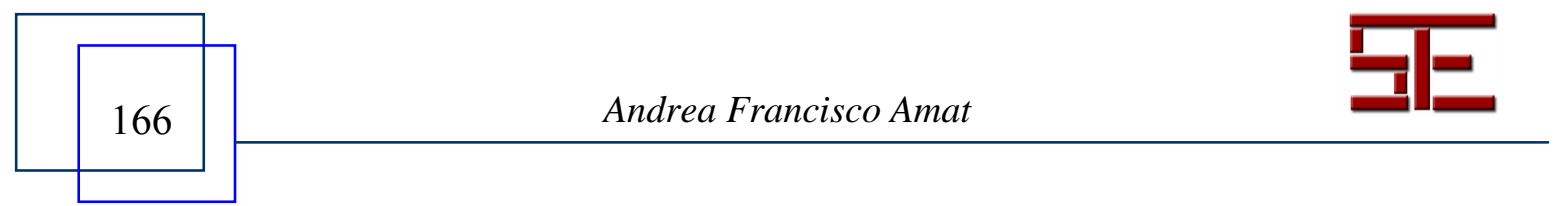




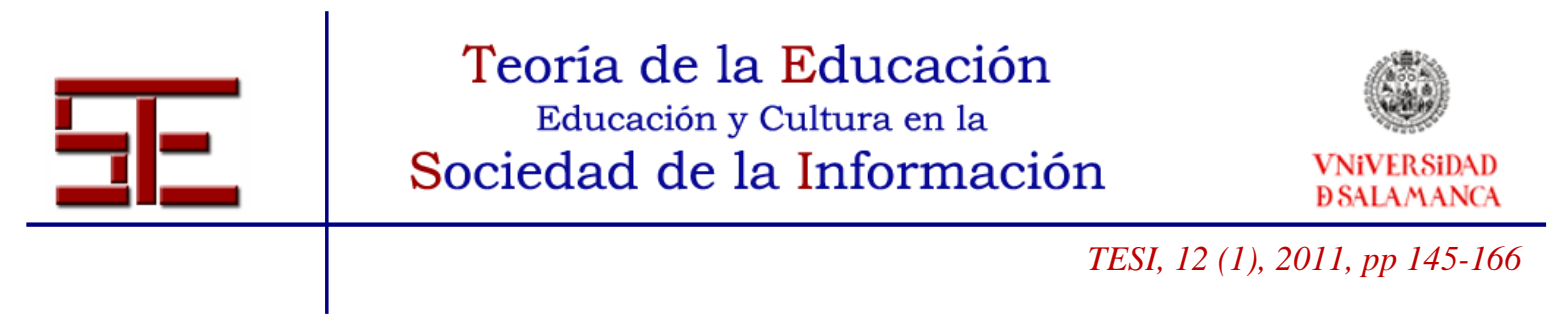

Para citar el presente artículo puede utilizar la siguiente referencia:

Francisco Amat, A. (2011). Usando la web 2.0 para informarse e informar. Una experiencia en educación superior, en Hernández Serrano, M. J. y Fuentes Agustí, M. (Coords.) La red como recurso de información en educación. Revista Teoría de la Educación: Educación y Cultura en la Sociedad de la Información. Vol. 12, no 1. Universidad de Salamanca, pp. 145-166 [Fecha de consulta: dd/mm/aaaa].

http://campus.usal.es/ revistas_trabajo/index.php/revistatesi/article/view/7827/7854

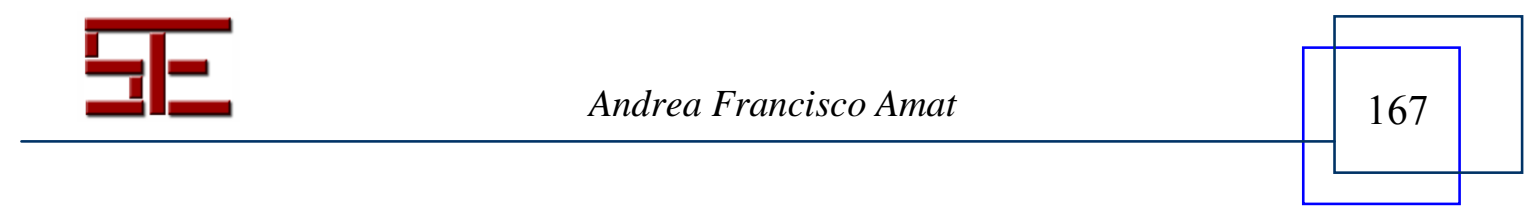

